Max-Planck-Institut für demografische Forschung

Max Planck Institute for Demographic Research

Konrad-Zuse-Strasse 1 - D-18057 Rostock - GERMANY

Tel +49 (0) 3812081 - 0; Fax +49 (0) 3812081 - 202;

http://www.demogr.mpg.de

MPIDR WORKING PAPER WP 2016-009

AUGUST 2016

\title{
Spatial and social distance in the fertility transition: Sweden 1880-1900
}

Sebastian Klüsener (kluesener@demogr.mpg.de)

Martin Dribe (martin.dribe@ekh.lu.se)

Francesco Scalone (francesco.scalone@unibo.it)

This working paper has been approved for release by: Vladimir Shkolnikov (shkolnikov@demogr.mpg.de), Head of the Laboratory of Demographic Data.

(C) Copyright is held by the authors.

Working papers of the Max Planck Institute for Demographic Research receive only limited review. Views or opinions expressed in working papers are attributable to the authors and do not necessarily reflect those of the Institute. 


\title{
Spatial and Social Distance in the Fertility Transition: Sweden 1880-1900
}

\author{
Sebastian Klüsener ${ }^{*}$, Martin Dribe ${ }^{* *}$ and Francesco Scalone ${ }^{* * *}$ \\ * Max Planck Institute for Demographic Research, Rostock (kluesener@demogr.mpg.de) \\ ** Centre for Economic Demography and Department of Economic History, Lund University \\ (Martin.Dribe@ekh.lu.se) \\ *** Department of Statistical Sciences, University of Bologna (Francesco.Scalone@unibo.it)
}

\begin{abstract}
Most existing studies on the fertility transition focus either on macro-level trends or on micro-level patterns with limited geographic scope. Much less attention has been given to the interplay between individual characteristics and contextual conditions, including geographic location. This paper contributes to closing this research gap. We investigate the relevance of geography and socioeconomic status (SES) for understanding fertility variation in the initial phase of the fertility decline in Sweden. Spatially-sensitive multi-level analyses are applied to study fertility trends by SES and parish, using full-count individual-level census data for 1880,1890 , and 1900. Our results show that the elite not only constituted the vanguard group in the fertility decline, but that the shift in fertility behavior occurred quickly among this social class in virtually all parts of Sweden. Other social classes experienced the decline with some delay in both central and peripheral areas, and their patterns of decline were more clustered in and around the early centers of the decline compared to the pattern of the elite. Longdistance migrants, who were disproportionately represented among the elite and who initially had higher fertility, were among the pioneers in the process. This suggests that factors such as social connectedness through space and local social embeddedness were important in determining the early adoption of changes in fertility behavior. Our results confirm the view that social status and social class boundaries were of considerable relevance in structuring the fertility transition. The importance of space for understanding variation in the fertility decline seems to be negatively correlated with social status, with the pattern of decline among the elite showing the lowest degree of spatial variation.
\end{abstract}




\section{Acknowledgements}

This work is part of the project "Towards the modern family. Socioeconomic stratification, family formation and fertility in a historical perspective," funded by the Swedish Research Council and the Crafoord Foundation (PI: Martin Dribe). Earlier versions of this paper were presented at the IUSSP International Population Conference, Busan, South Korea, 2013; the annual meeting of the Social Science History Association, Chicago, USA, 2013; the European Social Science History Conference, Vienna, Austria, 2014; and the annual meeting of the Population Association of America, Boston, USA, 2014. The authors would like to thank Miriam Hils for language editing. 


\section{Introduction}

The decline in fertility during the demographic transition has long been a major theme in contemporary and historical demography. Much of the literature has focused on the demographic aspects of the decline, and has sought to chart this process. Other research has offered explanations for the decline, mainly at the macro level. Meanwhile, much less attention has been paid to disaggregated patterns and micro-level analyses. Conceptually, the fertility transition is often viewed within the frameworks of adjustment and innovation (Carlsson 1966). In the adjustment framework the decline is seen primarily as the result of an adjustment of behavior to new circumstances and a greater motivation to limit family size, whereas in the innovation framework the diffusion of new knowledge or attitudes to fertility control is viewed as a crucial element of the process.

According to the adjustment perspective, fertility decline is a response to changes in the motivation to have children, which is connected to the demand and supply of children (Easterlin and Crimmins 1985). In pre-transitional societies, the demand for children is high, but the supply is low because of high mortality; thus, demand exceeds supply. Fertility decline is explained by the adjustment to the processes that influence the demand and/or supply side. These processes include reductions in infant and child mortality (Galloway et al. 1998; Haines 1998; Reher 1999; Reher and Sanz-Gimeno 2007), as well as changes in the costs of having children. For example, the costs of raising children may increase as a result of economic changes in food and housing prices, or of government interventions that limit child labor or increase the period of schooling (see Alter 1992; Schultz 2001; Guinnane 2011).

According to the innovation perspective, the fertility decline is mainly the result of the spread of the idea and social acceptability to apply contraceptive techniques after reaching a target family size (cf. Coale and Watkins 1986; Cleland and Wilson 1987). Based on this view, the emergence of deliberate birth control as a mass phenomenon requires the transmission of new ideas and changing attitudes and norms concerning the appropriateness of fertility control. It also involves the acquisition of knowledge about how to limit fertility. Many scholars believe this knowledge existed among families long before the decline, but that it was used less for parity-specific birth control than for the spacing of births or the avoidance of childbearing in difficult times (see, e.g., Bengtsson and Dribe 2006; David and Sanderson 1986; Dribe and Scalone 2010; Santow 1995; Szreter 1996; Van Bavel 2004). 
It has often been stressed that the adjustment and the innovation perspectives are best viewed as complementary, and not as competing (e.g., Cleland 2001; Lesthaeghe and Vanderhoeft 2001; Palloni 2001; Lesthaeghe and Neels 2002; Goldstein and Klüsener 2014). In both explanations access to information plays an important role. To adapt to structural change, individuals need to become aware of the nature of these developments. They gain this awareness not only through their own life experiences, but also through communication with others and information spread by media (Bongaarts and Watkins 1996; Montgomery and Casterline 1996). Likewise, for new ideas to diffuse in societies, population members need to become aware of these ideas through similar pathways. Individuals do not have identical levels of access to information, and the exchange of information is moderated by social and spatial distances (see also Szreter 1996). This unequal access to information likely affects the spatiotemporal patterns of behavioral adaptations across social classes during the fertility transition. Imperfect access to information can also produce temporal lags between the emergence of structural conditions that provide motivations for reducing the number of born children, and the actual adoption of such behavior.

There is growing empirical evidence that the spread of information is an important component of the fertility transition, with spatial and social distances acting as moderators (Szreter 1996; Garrett et al. 2001; Schmertmann et al. 2010; González-Bailón and Murphy 2013; Goldstein and Klüsener 2014). However, little is known about the interplay between individual characteristics and contextual conditions, including geographic location. There has also been a lack of analyses that have sought to differentiate the spatial patterns of fertility decline by socioeconomic status (SES), even though both the theoretical considerations and the empirical findings of Szreter (1996) indicate that this kind of research could generate important insights. This paper contributes to closing these knowledge gaps.

In our analysis, we make use of rich data for Sweden to study the initial phase of the fertility transition in this country. Our main aim is to investigate whether geography or social class differences are more relevant for understanding fertility variation. To what degree was the emergence of low fertility clustered in specific social classes or locations? Did spatial and social variation in the emergence of this behavioral shift differ by, respectively, social class and location, and what were potential determinants of these disparities? We analyze individual-level full counts of the Swedish population from the censuses of 1880, 1890, and 1900; including detailed information on occupation. Spatially sensitive multi-level regression meth- 
ods are applied to investigate the importance of socioeconomic determinants and spatial dimensions for understanding net fertility variation by controlling for various factors at the individual and parish levels.

Our results confirm previous findings that the elite were forerunners in the fertility decline. In addition we are able to show that members of this social class were hardly constrained by geography in adopting this new behavior, as reductions in fertility appeared fast among elite women in virtually all parts of Sweden. Non-elite social classes, on the other hand, lagged behind in both central and peripheral locations, which suggests that social status and social class boundaries were relevant in structuring this process. Our results further show that the decline patterns among non-elite social classes were spatially clustered around early centers of the decline to a much greater extent than the pattern among the elite, which indicates that the relevance of space for understanding fertility variation during the fertility transition is negatively correlated with social status. In terms of the mechanisms that might have contributed to these SES disparities, our models demonstrate that long-distance migrants, who were disproportionately represented among the elite and who initially had higher fertility, were among the pioneers in the process. This suggests that factors such as social connectedness through space and local social embeddedness were important in determining the early adoption of changes in reproductive behavior.

\section{Theoretical Considerations}

Coale (1973) distinguishes three preconditions that have to be met for a fertility transition to occur: people need to be ready, willing, and able to limit family size (see also Lesthaeghe and Vanderhoeft 2001). First, couples have to be consciously aware that reducing their number of offspring is beneficial for them (readiness). Second, the new behavior must be culturally accepted (willingness). Third, the technical means for preventing conception and the knowledge about them must be available (ability). Although scholars have debated whether these preconditions are universally applicable (Eckstein and Hinde 2002), they are helpful for developing a theoretical understanding of how spatial and social proximity might affect the exchange of information between individuals during the fertility transition. This information exchange we assume to be an important factor in this process. 
At the onset of the fertility transition in Sweden, the benefits of reducing fertility were perhaps most evident in large cities, where individuals were confronted with rapid social changes, with all of the advantages and the drawbacks inherent in these developments. While societal changes brought about new opportunities for social mobility, especially for educated individuals (Dribe, Helgertz, and van de Putte 2015), they also contributed to rising prices for housing and food. In addition to being more ready to reduce their fertility, residents of cities were probably more willing to make this transition, as cities generally provide greater anonymity and a more liberal context than non-urban areas. Thus, compared to their rural counterparts, city dwellers faced a lower risk of losing social capital (Bourdieu and Wacquant 1992) as a result of adopting a new behavior that potentially deviated from prevailing norms. Losses in social capital might also have had financial implications if these losses affected employment opportunities or transfers from family members, such as inheritances. Another reason why residents of large cities were forerunners in the decline is that cities were central nodes of communication and transportation networks. They were thus important hubs for the diffusion of information on changes in structural conditions, and of new ideas and technologies, such as contraceptive methods.

As most of the social interactions in our study period were still local in character, it is likely that spatial distance was acting as an important moderator in the adoption of fertility change. Early adopters in a given location were likely to face uncertainties about how their local social network would perceive such a behavior. Thus, the adoption rates could initially be most intense within localities where pioneers had already adopted the behavior without being subjected to substantial sanctions, and in areas adjacent to these early centers of fertility decline. At the onset of the process, this chain of events eventually resulted in a spatial pattern of fertility decline that Hägerstrand (1965) has called a nebula-like cluster, in which early centers constituted cores with high adoption rates that were surrounded by areas in which the risk of early adoption progressively decreased by distance. However, the emergence of such a spatial pattern is not necessarily attributable to an information diffusion process, as this pattern may have been the result of an adaptation process to structural changes with a spatial dimension (e.g., reductions in infant mortality spreading from the towns into surrounding areas). 
In addition to spatial distance, social distance may have constrained the spread of behavioral shifts (Rogers 2003). Elite groups were often identified as early adopters during the fertility transition (Livi-Bacci 1986; Haines 1992; Dribe and Scalone 2014; Dribe et al. 2014; Dribe et al. 2015a). Theoretical explanations for this pattern have frequently cited the distinctive characteristics of elites. At least in historical times, elite groups were much more likely than less advantaged groups to maintain social networks across long distances, and thus had better access to information and new ideas (Szreter 1996). These social networks may have included elite family members and other contacts living in different cities and countries. Elite individuals may have also developed extensive social networks by attending one of the few higher education institutions, or by serving in the higher ranks of the military or the central administration.

Evidence that elites of the same profession had very similar fertility trends during the fertility transition, even if they lived in distant places, was presented by Szreter (1996) in his seminal study on the socioeconomic differentials of the fertility decline in Britain. Based on his findings, he argued that recognizing the existence of "communication communities" of similar social backgrounds is important for understanding the mechanisms of the fertility decline. While the interplay between spatial context and SES was not the main focus of his quantitative analyses, Szreter (1996: 580) recommended that researchers who wish to test his hypothesis of communication communities conduct "properly contextualized comparative local studies." Our study of 2,435 parishes covering all of Sweden is perhaps the most far-reaching attempt of this kind so far. In our study on the role of social differences, we benefit from the fact that Swedish society at this time was highly stratified, with nobility, high-level managers, and professionals forming a distinctive elite into which there was limited mobility (see, e.g., Clark 2014; Dribe et al. 2015b).

The elite also likely differed in their access to assets and their local embeddedness, which might have affected what Coale referred to as willingness. Many elite couples had moved to non-metropolitan areas so that the husband could take a position as, for example, a doctor, a parish priest, or a local administrator. As a result, a considerable share of Stockholmborn elite women were living in remote areas of Sweden (see Klüsener et al. 2017). It seems probable that, compared to other women, elite women in such non-metropolitan areas were not only more exposed to information that may have led them to reduce their fertility, but were also in general more willing to consider limiting their family size. The latter can be related to both social capital and social control considerations (see Lesthaeghe 1980). Elite women might have been less embedded in social control networks at the local level for several reasons. As we will 
show below, many elites were not living in their place of birth, and may therefore have been less subject to control by other (older) family members. This was very different for the farmers, among whom many lived very local lives (see below). In addition, the status of being part of the elite already gave them a distinctive identity that may have made it easier for them to risk adopting a new deviant behavior, even if the reaction of the local social contacts was uncertain.

Based on our theoretical considerations, we formulate the following hypotheses. If the fertility decline patterns in this early period of the fertility transition in Sweden cluster around early centers of the fertility transition, with the clusters persisting even after controlling for variation in social and economic characteristics, we perceive this as support for the view that geography was an important moderator in the transition. If we see different adoptions rates by SES, independent of whether the individuals were living in central or peripheral locations, we can conclude that socioeconomic differences were an important moderator of the process. Assuming that access to information is relevant for the decision to have fewer children, we would expect to observe that social groups and populations in locations with better access to such information were forerunners in the decline.

\section{Data and Methods}

We use micro-level data from the Swedish censuses of 1880, 1890, and 1900. In the 1880 census approximately 4.6 million persons in 1.2 million households were counted, while the corresponding figures for the 1890 and 1900 censuses are 4.8/1.3 and 5.2/1.4 million, respectively. These data were digitized by the Swedish National Archives, and are freely available for scientific use through the North Atlantic Population Project (NAPP), which uses the same format as the Integrated Public Use Microdata Series (IPUMS) (Ruggles et al. 2011). All of the individuals counted are grouped by household. Thus, each individual record includes information on the household index number and the person index within that household. The available individual-level attributes include sex, age, marital status, labor market status, parish of residence, and parish of birth. ${ }^{1}$ The person's relationship to the household head is recorded as well. In addition, there are family pointer variables that indicate the personal number within the household of the mother, the father, or the spouse; these variables make it possible to link each woman to her own children and husband.

\footnotetext{
${ }^{1}$ For foreign-born persons the country of birth is provided.
} 
The census data are structured by church parish. In preparing our analysis we accounted for changes in the parish boundaries in the period of observation to construct a dataset of time-constant areas for the period 1880-1900. This dataset is linked to a GIS-file with the administrative boundaries of these areas, which we derived from a historical GIS-file of Swedish administrative boundaries that was set up by the Swedish National Archives (Riksarkivet 2016). In total, we are able to divide Sweden into 2,435 parishes for which we derive information on contextual conditions based on aggregated census data and the calculation of geographic distances to large urban centers. Working with parish data also allows us to some degree to subdivide larger cities, and thus to provide a geographically differentiated picture of fertility trends in and around the urban centers of Sweden.

\section{Dependent Variable}

The census data do not permit us to compute standard fertility rates. We therefore apply the child-woman ratio (CWR), which is an indirect measure of fertility. The CWR has been traditionally defined as the number of children aged 0-4 per woman aged 15-49 (Shyrock and Siegel 1980). We are able to use this measure at the individual level, which implies that the children under age five may have been born during the five-year period before the census date, when the mother was up to five years younger. We focus on marital fertility and created for each of the three censuses a sample of married women aged 15-54 to ensure that we cover all surviving children aged 0-4 who were born to women aged 15-49. This sample is limited to women whose spouses were present as we will use SES-information from these spouses. Descriptive statistics of our samples are presented in Table 1. A total of around 600,000 women are included in each of the three census samples.

A comparison of net fertility (child-woman ratios) and marital fertility (based on the own-children method using SES-specific mortality data) for Malmöhus county (southern Sweden) from 1896 to 1900 indicates that the results are very similar across SES categories (Scalone and Dribe 2012). Although the unadjusted CWRs were underestimated for highmortality groups in relation to low-mortality groups, the relative positions of the different SES groups were the same for the adjusted and the unadjusted CWRs (see also Scalone and Dribe, forthcoming). 
Net fertility might also be a more informative measure of fertility, as we expect that families rather cared about their number of surviving children than their number of births. Although a portion of the fertility transition likely came in response to a perceived need to offset lower mortality rates (Galloway et al. 1998; Reher 1999; Reher and Sanz-Gimeno 2007; Dyson 2010), it is clear that the decline in net fertility was more important in the long run, as it far exceeded the adjustments for mortality improvements (Haines 1998).

\section{Measuring Socioeconomic Status (SES)}

During the period under study, husbands were usually the main breadwinners in the family, and most married women lacked occupational notations in the census. Hence, we measure SES based on the occupation of the husband. As the census data offer detailed information on occupation, we are able to distinguish a fairly large number of occupational groups using the Historical International Standard Classification of Occupations (HISCO; van Leeuwen et al. 2002). Based on this coding scheme, we apply the international classification scheme HISCLASS (van Leeuwen and Maas 2011) to divide the individuals in 12 different social classes. HISCLASS considers the skill level, degree of supervision, type of work (manual vs. nonmanual), and whether the residence was in an urban or a rural area. The 12 classes are as follows: 1) higher managers; 2) higher professionals; 3) lower managers; 4) lower professionals, clerical and sales personnel; 5) lower clerical and sales personnel; 6) foremen; 7) medium skilled workers; 8) farmers and fishermen; 9) lower skilled workers; 10) lower skilled farm workers; 11) unskilled workers; and 12) unskilled farm workers. To reduce the problems associated with having a small number of observations in some classes, we further aggregated the classes into six or three social classes, depending on the type of analysis. The six classes, which we use in some descriptive analyses and as SES control in our models, are as follows: elite and upper middle class (HISCLASS 1-6), farmers (HC 8), skilled workers (HC 7), lower skilled workers (HC 9-10), and unskilled workers (HC 11-12). In this classification scheme we assign individuals who cannot be allocated to a specific class to a sixth group (others). The three further aggregated social classes, for which we map the fertility decline and run separate models, are as follows: elite (HISCLASS 1-6), farmers (HISCLASS 8), and workers and other social groups (HISCLASS 7, 9-12, and others). 


\section{Analytical Strategy}

In our analysis we face the challenge that while the fertility decline was unfolding dynamically in space and time, our detailed data come in a cross-sectional form that allow us to gain insight into net fertility only at specific time periods during the fertility transition. Therefore, we cannot directly identify individual and contextual factors that shape changes in fertility. Instead, we will focus on investigating how statistical associations between net fertility and individual- and parish-level characteristics shift during the fertility transition. We are, however, able to investigate the spatiotemporal dynamics of the fertility decline by SES in the descriptive part of our analysis, where we use maps to study spatial variation in net fertility changes in different SES groups. To our knowledge, this is the first time geographically detailed maps on the fertility transition by SES are presented for an entire country.

In the second part we run separate regression models (OLS) for 1880, 1890, and 1900 to estimate the association between net fertility and SES as well as other individual- and contextual-level characteristics. ${ }^{2}$ As the dependent variable, we use for each married woman the number of own children under age five present in the household. The models are based on a multi-level approach with random intercepts at the parish level, which allows us to simultaneously control for both individual- and parish-level covariates. In addition to the models that include all women independent of SES, we estimate separate models for each of our three big social classes (elite, farmers, workers and others).

As we are running regression models on data with high levels of geographic detail, spatial autocorrelation might introduce bias due to the violation of OLS assumptions. One basic assumption is that the observations are independent. This assumption is often violated in spatial models, as neighboring spatial units are likely to share many compositional and contextual characteristics. If the models are unable to control for the factors that cause this so-called positive spatial autocorrelation, residuals with high or low values will be spatially clustered. Positive spatial autocorrelation biases standard errors downward, which gives overly optimistic tests of statistical significance. Spatial autocorrelation might also bias the parameter estimates and model diagnostics (for details, see Anselin 1988).

\footnotetext{
${ }^{2}$ We have chosen an OLS instead of a Poisson specification because our spatial analysis methods used to control for spatial autocorrelation aspects have been developed for OLS analyses, and have not been thoroughly tested for Poisson models. We performed sensitivity checks by running our models with a Poisson specification, which showed that this choice does not largely affect our model outcomes.
} 
To examine to what degree our model estimates are affected by spatial autocorrelation, we derive aggregate mean values of the dependent variable and the model residuals at the parish level. We then calculate the Moran's I index of spatial autocorrelation (Moran 1950). ${ }^{3}$ This measure is very similar to Pearson's product moment correlation coefficient, except that instead of looking for the correlation between the values of two variables $x$ and $y$ in each parish $i$, it examines the correlation between the values of a variable $y$ in each parish $i$ with information on values of the same variable $y$ in the parishes $j$ that are adjacent to parish $i$ (in our case, the mean value of $y$ in the five nearest neighboring parishes $j$ ). ${ }^{4}$ Moran's I index can take on values from -1 (strong negative spatial autocorrelation) over 0 (no spatial autocorrelation) to 1 (strong positive spatial autocorrelation). In empirical social studies, researchers are usually confronted with positive spatial autocorrelation, which implies that units with similar values are clustering in space.

For our covariates we present descriptive statistics in Table 1. At the individual level, we consider SES and several bio-demographic variables. The age of the woman and the age difference between the spouses control for well-known age dependencies in fertility. Linked children over age four can be viewed as an indirect measure of marital duration; i.e., that the couple had the possibility of having children for the entire five-year period preceding the census. Controlling for whether the husband was the head of household, we expect that a woman whose husband was not the head of the household would have had lower fertility because her access to resources was more restricted.

${ }^{3}$ Moran's I index is defined as: $I=\left(\frac{n}{\sum_{i=1}^{n} \sum_{j=1}^{n} w_{i j}}\right) \frac{\sum_{i=1}^{n} \sum_{j=1}^{n} w_{i j}\left(y_{i}-\bar{y}\right)\left(y_{j}-\bar{y}\right)}{\sum_{i=1}^{n}\left(y_{i}-\bar{y}\right)^{2}}$ where $n$ is the number of spatial units indexed by $i$ and $j$, and $w_{i j}$ is a matrix of spatial weights.

${ }^{4}$ In the models for the SES groups, we have in a small number of cases parishes with no individual-level observations. These parishes are excluded from the GIS-file before deriving information on the five nearest neighbors $j$ of a region $i$ for a specific model, so that data are available for all five neighbors. This procedure will be of considerable relevance for our sensitivity checks discussed below, in which we exclude parishes with small numbers of observations to examine how our spatial autocorrelation tests are affected by random noise due to small population sizes in some parishes. 
(Table 1 about here)

One of the innovative elements of our study is that we include detailed information on the life-time net migration background (i.e., the distance between the place of birth and the current place of residence, which is derived through GIS operations). ${ }^{5}$ We believe that this variable can be used as a proxy for social connectedness through space and local social embeddedness (see also Hägerstrand 1965), as we expect that women who were living farther away from their place of birth had better access to information, as their social networks likely spanned larger distances. In addition, women who were not born in their current place of residence might have been less embedded in the local society, and may therefore have been more open to deviating from prevailing behaviors. Thus, we might find a positive relationship between the life-time net migration distances and the early adoption of reduced fertility. In Figure 1 we present some descriptive statistics for this variable for all women and our three social classes for the 1880,1890 , and 1900 censuses. These results are in line with the expectation that the social networks of the elite spanned larger distances, while particularly many farmers seem to have lived very local lives. We include information on life-time net migration at both the individual and the contextual levels, as we believe that living in a parish with a high share of long-distance migrants could also be of relevance for shifts in fertility behavior among locally-born women. In the categorization of these distances, women who were born abroad form a separate category, as we lack information on their parish of birth. As a contextual parish-level variable we use information on the proportion of migrants who were born more than $100 \mathrm{~km}$ away or abroad.

(Figure 1 about here)

In addition, we control for a number of covariates that capture variation in economic and social conditions. For female labor force participation, we also include both an individual- and a contextual-level measure. The individual-level control of labor market participation might be seen as a measure of the indirect opportunity costs of having children. This indicator should, however, be interpreted with caution due to potential endogeneity problems, as the

\footnotetext{
${ }^{5}$ As we lack information on the transport infrastructure in the period under study, we derive distances by obtaining the spherical distances between the centroids of the parishes.
} 
labour market status of women might be affected by their number of children under age five. Married women's labor force participation is difficult to measure because of the number of women who were working on family farms, and also because of the cultural expectations that likely resulted in the undercounting of the number of married women who were participating in the labor force (see Dribe and Scalone 2014). Counting all wives in the farming sector as employed would give much higher estimates than those presented here, in which we have included only the occupations noted in the sources (i.e., not "wife"). In deriving the parishlevel female labor force participation rate we decided to focus on never married women aged 15-64, as their labor market status is less likely to be affected by prior births. Variation in the female labor force participation might influence the behavior of individuals through imitation and attitudinal change. We expect a negative relationship between this variable and net fertility levels during the transition.

Other contextual-level covariates control for population density, the degree of industrialization, and educational orientation. Population density also serves as a proxy for urbanization. We assume that all three variables are negatively related to fertility during the transition (see, e.g., Galloway et al. 1994; Dribe 2009; Goldstein and Klüsener 2014). The degree of industrialization is based on the HISCO-coded occupations, and is calculated for the male population aged 15-64. Educational orientation is measured by the number of teachers in basic education per 100 children of school age (7-14 years). Finally, we include a regional dummy variable designed to capture the regional variation that remains unexplained by the other covariates. The main purpose of this variable is to determine to what degree unexplained fertility decline was clustering around major cities. It thus covers categories with parishes within specific distances of the three biggest cities in Sweden: namely, Stockholm, Gothenburg, and Malmö. Next, we include controls for regions with specific fertility levels that cannot be explained with our models in order to reduce bias introduced by spatial autocorrelation in the model estimates.

\section{Results}

\section{Descriptive Findings}

We will first look at how the fertility decline unfolded in space and time in this initial phase of the transition, using age-standardized child-woman ratios based on the age structure of 
married women aged 15-54 in the 1890 census. ${ }^{6}$ The child-woman ratios by SES for the three censuses are presented in Table 2. To show the substantial effect of the age standardization, we also included the non-standardized values in this table. Net fertility was rather stable between 1880 and 1890, and then decreased 3\% between 1890 and 1900 . However, these trends differed substantially by SES. Already at the beginning of our observation period in 1880 , the elite had below-average CWRs, and experienced a decline of about $13 \%$ between 1880 and 1900. Farmers, on the other hand, had above-average CWRs in 1880, and experienced a slight increase in the subsequent decades. As a result, the gap between the CWRs of the elite and the farmers increased from 0.08 to 0.20 . Skilled and lower skilled workers experienced declines of $7 \%$ and $4 \%$, respectively; but in contrast to the trends among the elite, these declines occurred almost entirely in the second decade of our study period.

(Table 2 about here)

The position of the elite as forerunners in the decline might be related in part to the concentration of members of this social class in big cities, which often constituted early centers of the fertility decline. The maps in Figure 2 that display the spatial aspects of (net) fertility trends by SES allow us to look into this question. Figure 2a shows the changes in the child-woman ratio between 1880 and 1900 for all women in the 159 judicial districts (domsaga) of Sweden. ${ }^{7}$ The decline pattern for all women (Figure 2a) resembles to some degree Hägerstrand's (1965) description of a nebula-like cluster, which is very typical for cartographic representations of the fertility decline (see, e.g., Coale and Watkins 1986;

\footnotetext{
${ }^{6}$ This decision was also motivated by the massive changes in the social structure of Sweden during that period, which are likely to exhibit cohort patterns. As we can see in Table 1, the share of farmer women decreased over the 20 -year period from $41.2 \%$ to $32.4 \%$, while the shares of elites and workers and others increased substantially. Our sample of (married) farmer women had the highest mean age among our three social classes in all three censuses.

${ }^{7}$ We decided to map the patterns at this higher administrative level, as we have only a small number of observations for each of our three social classes at the parish level in many locations. This makes parishlevel maps difficult to interpret due to random noise. In aggregating the data to the judicial districts, we faced the challenge that also some small urban settlements form own districts, whose CWRs are still likely to be affected by substantial noise. We therefore decided to combine urban judicial districts, which had less than 5,000 inhabitants in the 1900 census, with the surrounding judicial district.
} 
Schmertmann et al. 2008; Goldstein and Klüsener 2014). The decline is concentrated in large centers such as Stockholm and Malmö ${ }^{8}$, the surrounding areas, and the central transport and communication corridors. The latter include the lake area in central Sweden between Stockholm and Gothenburg. An exception to this general pattern is Gothenburg and the surrounding territories, where the fertility decline in this period was more limited. We will come back to this in the discussion.

(Figure 2 about here)

When we disaggregate the numbers by our three social classes (Figures 2b-d), the nebula-like clustering is also visible in the patterns of the farmers and workers and others, while the elite show a very different pattern. In almost all areas of Sweden, regardless of whether the area was remote or central, the elite experienced a decline. However, the areas with the greatest declines among elite women seem to have been concentrated in the southern half of Sweden, whereas the declines were smaller in the north. The overall decline pattern among the elite suggests that information about the advantages of reducing fertility and contraceptive technologies had already spread to virtually all parts of Sweden during that period.

The spatial fertility change pattern of the farmers closely resembled the pattern for all social groups. This is not surprising, as farmers were the predominant social class in rural areas, which covered most of Sweden at that time. Our third and most heterogeneous social class, workers and others, also displayed the most heterogeneous spatial pattern. In many areas of Sweden, their CWR was still increasing between 1880 and 1900. This was also the case in Stockholm and Gothenburg in the period 1880-1890. On the other hand, we find distinct local urban hot spots of fertility decline as well, such as the industrial city of Norrköping, located southwest of Stockholm. In this city, in which large numbers of women were working in textile production, workers and others experienced a fertility decline of $16 \%$ over the study period.

\footnotetext{
${ }^{8}$ With regard to Malmö it is important to note that the city is located close to the Danish capital of Copenhagen, which was the biggest city in Scandinavia at the end of the $19^{\text {th }}$ century. Copenhagen entered a period of drastic fertility decline around 1880 (Coale and Watkins 1986).
} 
Overall, the maps in Figure 2 provide the impression that in this early phase of the fertility transition in Sweden, fertility trends differed substantially by SES. Especially among the farmers and the workers and others, these trends also varied quite strongly across locations within Sweden. Moreover, there were dramatic shifts in the SES gradient in net fertility outcomes. In 1880, the elite still registered above-average CWRs in 58 out of 159 judicial districts in Sweden, while in 1900 this was the case in eight districts only.

\section{Model Results}

The outcomes of the models including all SES groups in 1880, 1890, and 1900 are presented in Table 3, while Table 4 shows the results for the models for our three different social classes. The model diagnostics include the outcomes of the Moran's I tests for spatial autocorrelation, which we perform on the parish-level averages of the dependent variable and the residuals. The tests indicate that in all 12 models there is positive spatial autocorrelation in the dependent variable, which implies that the spatial pattern is characterized by clusters of areas with high or low fertility levels. The Moran's I tests on the residuals show that the models explain a substantial part of the spatial variation in fertility levels. However, in all but the models for the elite some unexplained spatial autocorrelation remains even after the control variables are added. We will come back to this point at the end of this section.

In presenting the model outcomes we focus mainly on the outcomes of the three models for all social classes. If we refer to the models by SES we will explicitly state this. Before turning to the main findings, we should note that in all 12 models, the estimates of the bio-demographic controls are statistically significant and in the expected directions. If we look at the SES differentials across the three censuses (Table 3), we see that the net fertility outcomes of the elite became increasingly distinct from those of the other social groups over time, which fits with the outcomes from our descriptive analysis (see Dribe and Scalone 2014 for a more detailed investigation).

(Table 3 about here)

An interesting temporal pattern emerges for our individual-level life-time net migration variable, whereby in 1880 our reference category comprising women living within $10 \mathrm{~km}$ of their birth place had the lowest net fertility. This result does not fit with our expectation 
that the women who were living far away from their birth place were more likely to have been early adopters of fertility control. However, the pattern changed over time. In 1900, the women who were born abroad had significantly lower fertility than the women in the reference category, and the differences between the women in the reference category and the women living more than $50 \mathrm{~km}$ away decreased substantially. This pattern is even more pronounced in the models for elite women (Table 4), which show that in 1900 both women born abroad and women born more than $50 \mathrm{~km}$ away from their place of residence had significantly lower fertility than the reference group, whereas this was not the case in 1880 . Our contextual measure on the share of migrants in a community corresponds with this temporal trend pattern, as we obtain a significantly lower fertility outcome for parishes with a high share of long-distance migrants for 1900 only (Table 3).

(Table 4 about here)

The individual measure of women's employment exhibits significant negative associations with net fertility in all 12 models. When we focus on the community-level indicator of female labor force participation in the three models for all social classes, we find that it is not statistically significant for 1880 , whereas in 1890 we obtain the expected significant negative coefficient for parishes with a high labor force participation rate. For 1900, all of the coefficients are significant and have the expected negative gradient. Among the other contextual variables, we find a negative association between population density and net fertility in the full models, as well as in most of the SES-specific models. As we can see in Table 3, the magnitudes of the differences increase between 1880 and 1900, particularly for places in the highest category with population densities above 1,000 per $\mathrm{km}^{2}$. As such population densities were reached in urban parishes only, this pattern is in line with our expectation that populations in urban areas would be more likely to be early adopters of fertility control.

The teacher-child ratio shows an unexpected inverse U-shaped association in 1880, with women living in communities with medium-level ratios having the highest net fertility. Over time, however, the expected negative gradient emerges. For our industrialization covariate, the results are mixed. We find the expected negative gradient in the 1890 and 1900 
models, but the estimate for high share of men employed in industry in 1900 is not statistically significant. However, apart from a few exceptions, the community-level variables show the expected association with net fertility.

We will now turn to our regional dummy variable that accounts for unexplained remaining fertility variation around the three biggest cities (Stockholm, Gothenburg, and Malmö) ${ }^{9}$ and in areas with distinct fertility patterns (the island of Gotland and two areas in northern Sweden, namely northern and southern Norrland, including Kopparberg county). When we introduce the regional dummies to account for this unexplained variation, the Moran's I values for the residuals of the models are substantially reduced. ${ }^{10}$ The reduction is from 0.349 to 0.194 for the 1880 model, from 0.326 to 0.162 for the 1890 model, and from 0.259 to 0.142 for the 1900 model. This drastic decrease of spatial autocorrelation in our model residuals has almost no effect on the coefficients and significance levels of our individual-level covariates. But it alters the outcomes for a some of the parish-level covariates. Especially strong is the change for the population density variable, where in the model for all social classes the expected significant negative gradient only emerges after controlling for regional idiosyncrasies. For the female labor force rate and the proportion of migrants born far away and/or abroad the share of significant coefficients is decreasing. However, neither in the models for all social classes nor in the ones for our three different social classes, we observe a switch of the sign among coefficients that are significant both before and after the introduction of the regional dummies variable. Yet the coefficients for the regional dummies give mixed support for the view that there are distinct nebula-like diffusion clusters of unexplained fertility decline around the cities remaining in our models. In the model for all classes we find that only the cluster of low fertility in the area around Stockholm cannot be completely explained by our models; and this effect seems to be strongest in 1900 .

As was previously mentioned, the substantial reduction in spatial autocorrelation due to the introduction of the regional dummies has almost no effect on the outcomes for the individual controls, but it does affect the results for the parish-level covariates. It is therefore

\footnotetext{
${ }^{9}$ For Stockholm we consider a larger area around the city, as an analysis of the area from which these cities were drawing in-migrants suggested that Stockholm had a larger sphere of influence compared to the other two towns.

${ }^{10}$ Outcomes for the models without regional dummies are not shown.
} 
likely that if the remaining spatial autocorrelation is causing bias in our estimates, the effect is especially strong on the outcomes for our parish-level covariates. Related to this we benefit from the fact that we get quite consistent outcomes both for the individual-level and the parish-level covariates across our models, and that these outcomes are in line with our theoretical expectations. In addition, we take assurance from the situation that all important outcomes are also found in the models for the elite, which seem not to be biased by spatial autocorrelation as the Moran's I tests on the residuals are not significant.

We were, however, concerned by the fact that in the models for the elite the numbers of observed women were small in many parishes, as this could mean that the insignificant Moran's I is an artifact due to random noise. To investigate this possibility, we conducted sensitivity checks in which we stepwise excluded parishes with fewer than 2 to 40 women from our sample before deriving the spatial autocorrelation statistics. The upper threshold of 40 women was determined by variance checks that provided support for the view that random noise is particularly important for parishes with fewer than 30 women. These sensitivity checks suggest that the insignificant Moran's I for the residuals of the elite model in 1880 is likely to be an artifact of random noise. The insignificant Moran's I tests for the 1890 and 1900 elite models, on the other hand, turn out to be quite robust. In the sensitivity tests on the 1890 models, we did not obtain a significant Moran's I in any of our 39 tests, while for the 1900 model only 2 out of the 39 tests returned significant outcomes at the 0.05 -level. This finding confirms that the outcomes of these two models are not greatly affected by bias due to spatial autocorrelation, and can indeed provide us some reassurance.

\section{Discussion and Conclusion}

In this paper we have analyzed rich individual-level data covering all of Sweden at high levels of spatial and social detail to explore the relevance of geography and social status for understanding fertility variation during the fertility transition. We do not only confirm existing findings that the elite were a vanguard group in the fertility decline, but are also able to show that the elite exhibited spatially a rather homogenous pattern of fertility decline. This suggests that among the elite, access to information relevant for family limitation was hardly constrained by spatial distance. Meanwhile, farmers and workers were lagging behind the elite in the fertility decline in both central and peripheral areas. In many locations in Sweden, net fertility of some social classes was still rising when the net fertility of the elite had already begun to fall. This was even the case in the two biggest cities, Stockholm and Gothenburg, in 
the period 1880-1890. The areas where non-elite groups experienced an early decline were also much more clustered around early centers of the decline, such as Stockholm and Malmö. Our findings that fertility trends differed substantially by SES and that the decline patterns among the elite were spatially much more homogeneous than among the other social classes fit with Szreter's (1996) notion of communication communities.

Additional support for the expectation that social connectedness through space and local social embeddedness contributed to shape spatial fertility decline patterns is provided by our model outcomes. The finding that fertility initially was higher among long-distance migrants than among women who were still living close to their place of birth might be linked to healthy migrant effects, or to the possibility that migration provided women with better access to assets. In these terms, the shift toward significantly lower fertility among long-distance migrants and in places with high shares of long-distance migrants suggests that the fertility-enhancing effects of migration were increasingly outweighed by fertility-depressing effects. One potential mechanism that might explain this pattern is that compared to non-migrants, long-distance migrants may have been more exposed to information on the benefits of reducing fertility, as their social networks likely covered larger distances (e.g., their networks may have included family members and friends in their birth region). Another mechanism could be that long-distance migrants were less embedded in local intergenerational kinship and community networks, whose efforts to exert social control might have negatively affected the adoption of the behavioral shift among locally-born people. The fact that a relatively large share of the elite were long-distance migrants might have contributed to the status of the elite as a vanguard group, and could help to explain their spatially more homogenous pattern of decline.

In line with the adjustment perspective, another potential explanation for the spatially more homogenous decline pattern observed among the elite is that they were more likely than other social classes to consider changes not only in local conditions, but in the conditions of distant places. If, for example, the educational and career opportunities in Stockholm changed, these changes may have also been relevant for members of the elite classes who were living far away from the capital, as they might have been able to provide their children with access to higher education institutions that would allow the children to take advantage of the new career opportunities in Stockholm. However, in the context of this argument the question arises as to whether the quality-quantity trade-off was really of high relevance for the elite, as they were the social group who were, potentially, the least constrained by financial limitations (see, e.g., Dribe and Scalone 2014; Bengtsson and Dribe 2014; Molitoris and 
Dribe 2016). It may be the case that the personal advantages associated with having a smaller childrearing work load was more relevant in the decisions of elite women.

As part of a structural argument, it could also be asserted that the elite reduced their fertility first because they experienced the mortality transition earlier than the other classes (Bengtsson and Dribe 2010; Burström and Bernhardt 2001). We do not have information on mortality trends by SES for this period for the whole country, but it is important to note that in Sweden there was a substantial time lag of several decades between the onset of the mortality transition and the subsequent fertility transition (see, e.g., Hofsten and Lundström 1976; Dyson 2011). Since by 1880 infant mortality rates were already quite low in virtually all parts of Sweden, it is unlikely that we would see extensive variation in these rates in absolute terms by SES. Thus, we believe that the impact of SES differentials in infant mortality on the decline pattern by SES was quite low.

Do our findings therefore imply that local structural conditions were not very relevant for the fertility transition, as - at least among the elite - the decline spread rapidly even to peripheral areas? It is interesting to observe that in cities such as Stockholm and Gothenburg the timing of the onset of the fertility decline also differed by social class (see also Molitoris and Dribe 2016). This suggests that it would probably be difficult to link the onset to a single event, such as a policy reform. Nevertheless, once the fertility decline started to spread within a social class, it seems to have been most intense in highly urbanized and economically developed areas. This pattern is also visible in the parish-level coefficients of our models.

While most bigger Swedish cities, and particularly Stockholm and its surrounding areas, were early centers of the fertility decline; the area in and around the second largest Swedish city Gothenburg stands out, as it had rather high fertility levels and limited fertility decline in our study period. This deviation from the overall pattern might be explained by the religious movements that were widespread in the area at that time. Especially in the second half of the 19th century and in the early decades of the 20th century, a highly conservative interpretation of Lutheranism (so called Schartauanism, after the priest Henric Schartau) became popular among both farmers and laborers. This movement, which advocated a highly conservative world view (Jarlert 2005), may well have contributed to a delay in the adoption of new ideas on contraception and family limitation. Previous research has shown that religiosity and secularization were crucial determinants of fertility behavior in different parts of Sweden, both before and during the transition (Larsson 1984; Junkka and Edvinsson 2016). 
Among the limitations of our study are that data restrictions only allowed us to look at a short period of 20 years. In addition, we were only able to investigate fertility outcomes in 10-year intervals. Nevertheless, the richness of the census data and the high level of geographic detail allow us to gain insights into aspects of the fertility decline, such as the interplay between social status and geography, that have up to now been understudied in research on the fertility transition.

Overall, our results confirm previous findings that the fertility decline did not occur in one wave, but in several waves differentiated by SES. This conclusion supports the view that social class boundaries were highly relevant for the structuring of the fertility transition. The adoption of the behavioral shift by the elite seems to have been much less constrained by spatial distance than it was among the other groups. Thus, the nebula-like diffusion pattern that has been identified in many studies on the fertility transition seems to have been more pronounced among the lower social strata. That our models are particularly well suited to explaining spatial variation in fertility among the elite is also in line with our theoretical considerations, in which we noted that compared to other social groups, the elite were less constrained by spatial distance in exchanging information relevant to fertility decisions. We would therefore expect to find fewer unexplained regional idiosyncrasies among the elite than among the other social classes.

With our outcomes, we contribute to a growing body of evidence that the impact of spatial context and spatial distances on demographic outcomes at the individual level differ substantially by SES, with the highest classes generally being the least affected by geography (see, e.g., Andreev et al. 2010; Harper 2013). Our findings related to the interplay of social status and geography in shaping fertility decline patterns in space and time could also be relevant for research that seeks to explain the recent stalling of the fertility transition in Africa.

\section{References}

Alter, G. (1992). Theories of fertility decline: a nonspecialist's guide to the current debate. In J. R. Gillis, L. A. Tilly, \& D. Levine (Eds.), The European Experience of Declining Fertility, 1850-1970. The Quiet Revolution (pp. 13-27). Cambridge, MA: Blackwell. 
Andreev, E. M., Jdanov D., Shkolnikov, V.M., \& Leon, D. A. (2011). Long-term trends in the longevity of scientific elites: Evidence from the British and the Russian academies of science. Population Studies, 65 (3), 319-334, doi:10.1080/00324728.2011.603428

Anselin, L. (1988). Spatial econometrics: Methods and models. Dordrecht: Kluwer Academic Publishers.

Bengtsson, T., \& Dribe, M. (2006). Deliberate control in a natural fertility population: Southern Sweden, 1766-1864. Demography, 43 (4), 727-746, doi:10.1353/dem.2006.0030

Bengtsson, T., \& Dribe, M. (2010). Quantifying the family frailty effect in infant and child mortality by using median hazard ratio (MHR): The case of rural Sweden, 1766-1895. Historical Methods, 43 (1), 15-27, doi:10.1080/01615440903270299

Bengtsson, T., \& Dribe, M. (2014). The historical fertility transition at the micro level: Southern Sweden 1815-1939. Demographic Research, 30 (17), 493-534, doi:10.4054/DemRes.2014.30.17

Bongaarts, J., \& Watkins, S. C. (1996). Social interactions and contemporary fertility transitions. Population and Development Review, 22 (4), 639-682, doi: $10.2307 / 2137804$

Bourdieu P., \& Wacquant, L. J. D. (1992). An invitation to reflexive Sociology. Chicago: University of Chicago Press.

Burström, B., \& Bernhardt, E. (2001). Social differentials in the decline of child mortality in nineteenth century Stockholm. European Journal of Public Health, 11 (1), 2934, doi:10.1093/eurpub/11.1.29

Carlsson, G. (1966). The decline of fertility: Innovation or adjustment process. Population Studies, 20 (2), 149-174, doi:10.1080/00324728.1966.10406092

Clark, G. (2014). The son also rises. Surnames and the history of social mobility. Princeton: Princeton University Press.

Cleland, J. (2001). Potatoes and pills: An overview of innovation-diffusion contributions to explanations of fertility decline. In J. B. Casterline (Ed.), Diffusion processes and fertility transition: Selected perspectives (pp. 39-65). Washington, DC: National Academy Press. 
Cleland, J., \& Wilson, C. (1987). Demand theories of the fertility transition: An iconoclastic view. Population Studies, 41 (1), 5-30, doi:10.1080/0032472031000142516

Coale A. J. (1973). The demographic transition reconsidered. In International Union for the Scientific Study of Population (IUSSP) (Ed.), Proceedings of the International Population Conference 19731 (pp. 53-72). Liege: International Union for the Scientific Study of Population.

Coale, A. J., \& Watkins, S. C. (Eds.) (1986). The decline of fertility in Europe: The revised proceedings of a conference on the Princeton European Fertility Project. Princeton: Princeton University Press.

David, P. A., \& Sanderson, W. C. (1986). Rudimentary contraceptive methods and the American transition to marital fertility control, 1855-1915. In S. L. Engerman, \& R. E. Gallman (Eds.), Long-term factors in American economic growth (pp. 307 390). Chicago: University of Chicago Press.

Dribe, M. (2009). Demand and supply factors in the fertility transition: A county-level analysis of age-specific marital fertility in Sweden, 1880-1930. European Review of Economic History, 13 (1), 65-94, doi:10.1017/S1361491608002372

Dribe, M., \& Scalone, F. (2010). Detecting deliberate fertility control in pre-transitional populations: Evidence from six German villages, 1766-1863. European Journal of Population, 26 (4), 411-434, doi:10.1007/s10680-010-9208-8

Dribe, M., \& Scalone, F. (2014). Social class and net fertility before, during and after the demographic transition: A micro-level analysis of Sweden 1880-1970. Demographic Research, 30 (15), 429-464, doi:10.4054/DemRes.2014.30.15

Dribe, M., Hacker, J.D., \& Scalone, F. (2014). The impact of socio-economic status on net fertility during the historical fertility decline: A comparative analysis of Canada, Iceland, Sweden, Norway, and the USA. Population Studies, 68 (2), 135149, doi:10.1080/00324728.2014.889741

Dribe, M., Juarez, S. P., \& Scalone F. (2015a). Is it who you are or where you live? Community effects on net fertility at the onset of fertility decline: A multilevel analysis using Swedish micro-census data. Population, Space, and Place - Early View, published online 15 October 2015, doi:10.1002/psp.1987

Dribe, M., Helgertz, J., \& van de Putte, B. (2015b). Did social mobility increase during the industrialization process? A micro-level study of a transforming community in 
southern Sweden 1828-1968. Research in Social Stratification and Mobility, 41 (1), 25-39, doi:10.1016/j.rssm.2015.04.005

Dyson, T. (2010). Population and development: The demographic transition. London: Zed Books.

Dyson, T. (2011). The role of the demographic transition in the process of urbanization. Population and Development Review, 37 (Supplement 1), 34-54, doi:10.1111/j.1728-4457.2011.00377.x

Easterlin, R. A., \& Crimmins, E. M. (1985). The fertility revolution. A supply-demand analysis. Chicago: The University of Chicago Press.

Eckstein, B., \& Hinde, A. (2002). How helpful are Coale's predictions for fertility decline in explaining the British experience?

http://www.apa.org.au/upload/2002-4C_Eckstein.pdf. Accessed 15 August 2013.

Galloway, P. R., Hammel, E. A., \& and Lee, R. D. (1994). Fertility decline in Prussia, 18751910: A pooled cross-section time series analysis. Population Studies, 48 (1), 135-158, doi:10.1080/0032472031000147516

Galloway, P. R., Lee, R. D., \& Hammel, E. A. (1998). Infant mortality and the fertility transition: Macro evidence from Europe and new findings from Prussia. In M. R. Montgomery, \& B. Cohen (Eds.), From death to birth: Mortality and reproductive change (pp. 182-226). Washington, DC: National Academy Press.

Garrett, E., Reid, A., Schürer, K., \& Szreter, S. (2001). Changing Family Size in England and Wales. Place, Class and Demography, 1891-1911. Cambridge: Cambridge University Press.

Goldstein, J. R., \& Klüsener, S. (2014). Spatial analysis of the causes of fertility decline in Prussia. Population and Development Review, 40 (3), 497-525, doi:10.1111/j.1728-4457.2014.00695.x

González-Bailón, S., \& Murphy, T. E. (2013). The effects of social interactions on fertility decline in nineteenth-century France: An agent-based simulation experiment. Population Studies, 67 (2), 135-155, doi:10.1080/00324728.2013.774435

Guinnane, T. W. (2011). The historical fertility transition: A guide for economists. Journal of Economic Literature, 49 (3), 589-614, doi:10.1257/jel.49.3.589

Haines, M. R. (1992). Occupation and social class during fertility decline: Historical perspectives. In J. R. Gillis, L. A. Tilly, \& D. Levine (Eds.), The European experience 
of declining fertility, 1850-1970: The quiet revolution (pp. 193-226). Cambridge: Blackwell.

Haines, M. R. (1998). The relationship between infant and child mortality and fertility: Some historical and contemporary evidence for the United States. In M. R. Montgomery, \& B. Cohen (Eds.), From death to birth: Mortality and reproductive change (pp. 227-253). Washington, DC: National Academy Press.

Hägerstrand, T. (1965). A Monte Carlo approach to diffusion. European Journal of Sociology 6 (1), 43-67, doi:10.1017/S0003975600001132

Harper, S. (2013). Rethinking global ageing. Keynote speech at the $7^{\text {th }}$ International Conference on Population Geographies, 25-28 June 2013, Groningen, The Netherlands.

Hofsten, E., \& Lundström, H. (1976). Swedish population history: Main trends from 1750 to 1970. Stockholm: National Central Bureau of Statistics.

Jarlert, A. (2005). Henric Schartau 1757-1825 : syfte, samtid, samhälle [Henric Schartau 1757-1825 : Aim, contemporary times, society]. Skellefteå: Artos \& Norma. Junkka, J., \& Edvinsson, S. (2016). Gender and fertility within the free churches in the Sundsvall region, Sweden, 1860-1921. The History of the Family, 21 (2), 243266, doi:10.1080/1081602X.2015.1043929

Klüsener, S., Scalone, F., \& Dribe, M. (2017). Exploring the role of communication in shaping fertility transition patterns in space and time. In A. Grow, \& J. Van Bavel (Eds.), Agent-based modeling in population studies: Concepts, methods, and applications (pp. 369-403). Dordrecht: Springer.

Larsson, M. (1984). Fruktsamhetsmönster, produktionsstruktur och sekularisering: en jämförelse mellan 69 härader vid 1800-talets slut [Fertility patterns, production structure, and secularization: A comparison of 69 hundreds at the end of the $19^{\text {th }}$ century]. Ph. D. dissertation, Department of Sociology, Stockholm University.

Lesthaeghe, R. (1980). On the social control of human reproduction. Population and Development Review, 6 (4), 527-548, doi:10.2307/1972925

Lesthaeghe, R., \& Neels, K. (2002). From the first to the second demographic transition: An interpretation of the spatial continuity of demographic innovation in France, Belgium and Switzerland. European Journal of Population/ Revue européenne de Démographie, 18 (4), 325-360, doi:10.1023/A:1021125800070 
Lesthaeghe, R., \& Vanderhoeft, C. (2001). Ready, willing, and able: A conceptualization of transitions to new behavioral forms. In J. B. Casterline (Ed.), Diffusion processes and fertility transition: Selected perspectives (pp. 240-264). Washington, DC: National Academy Press.

Livi-Bacci, M. (1986). Social-group forerunners of fertility control in Europe. In A. J. Coale, \& S. C. Watkins (Eds.), The decline of fertility in Europe: The revised proceedings of a conference on the Princeton European Fertility Project (pp. 182-200). Princeton: Princeton University Press.

Molitoris, J., \& Dribe, M. (2016). Ready to stop: Socioeconomic status and the fertility transition in Stockholm, 1878-1926. The Economic History Review, 69 (2), 679704, doi:10.1111/ehr.12275

Montgomery, M. R., \& Casterline, J. B. (1996). Social learning, social influence, and new models of fertility. Population and Development Review, 22 (Suppl), 151-175, doi: $10.2307 / 2808010$

Moran, P. A. (1950). Notes on continuous stochastic phenomena. Biometrika, 37 (1/2), 17 23. doi: $10.2307 / 2332142$

MPIDR [Max Planck Institute for Demographic Research]. (2014). MPIDR Population History GIS Collection. Rostock: MPIDR. Retrieved March 31, 2014 from http://censusmosaic.org/web/data/historical-gis-files

Palloni, A. (2001). Diffusion in sociological analysis. In J. B. Casterline (Ed.), Diffusion processes and fertility transition: Selected perspectives (pp. 66-114). Washington, DC: National Academy Press.

Reher, D. S. (1999). Back to the basics: Mortality and fertility interactions during the demographic transition. Continuity and Change, 14 (1), 9-31, doi:10.1017/S0268416099003240

Reher, D. S., \& Sanz-Gimeno, A. (2007). Rethinking historical reproductive change: Insights from longitudinal data for a Spanish town. Population and Development Review, 33 (4), 703-727, doi:10.1111/j.1728-4457.2007.00194.x

Riksarkivet (2016). Historiska GIS-kartor (information om territoriella indelningar i Sverige från 1500-talets slut till 1900-talets slut) [Historical GIS map (information on the administrative division of Sweden from the $16^{\text {th }}$ to the $20^{\text {th }}$ century]. Stockholm: Riksarkivet.

Rogers, E.M. (2003). Diffusion of innovations. 5th edition. New York: Free Press. 
Ruggles, S., Roberts, E., Sarkar, S., \& Sobek, M. (2011). The North Atlantic Population Project: Progress and prospects. Historical Methods, 44 (1), 1-6, doi:10.1080/01615440.2010.515377

Santow, G. (1995). Coitus interruptus and the control of natural fertility. Population Studies, 49 (1), 19-43, doi:10.1080/0032472031000148226

Scalone, F., \& Dribe, M. (2012). Socioeconomic status and net fertility in the demographic transition: Sweden in 1900 - A preliminary analysis. Popolazione e storia, 11 (2), 111-132, doi:10.4424/ps2010-13

Scalone, F., \& Dribe, M. (forthcoming). Testing child-woman ratios and the own-children method on 1900 Swedish census data: Examples of indirect fertility estimates by socioeconomic status in a historical population. Historical Methods, forthcoming.

Schmertmann, C. P., Potter, J. E., \& Cavenaghi S. M. (2008). Exploratory analysis of spatial patterns in Brazil's fertility transition. Population Research and Policy Review, 27 (1), 1-15, doi:10.1007/s11113-007-9052-7

Schmertmann, C. P., Assunção, R. M., \& Potter, J. E. (2010). Knox meets Cox: Adapting epidemiological space-time statistics to demographic studies. Demography, 47 (3), 629-650, doi:10.1353/dem.0.0113

Schultz, T. P. (2001). Fertility transition: Economic explanations. In N. J. Smelser, \& P. B. Baltes (Eds.), International Encyclopedia of the Social and Behavioral Sciences (pp. 5578-5584). Oxford: Elsevier.

Shyrock, H. S., \& Siegel, J. S. (1980). The methods and materials of Demography. Washington, DC: U.S. Department of Commerce, Bureau of Census.

Szreter, S. (1996). Fertility, class and gender in Britain, 1860-1940. Cambridge: Cambridge University Press.

Van Bavel, J. (2004). Deliberate birth spacing before the fertility transition in Europe: Evidence from nineteenth-century Belgium. Population Studies, 58 (1), 95-107, doi:10.1080/0032472032000167706

van Leeuwen, M. H. D., \& Maas, I. (2011). HISCLASS. A Historical International Social Class Scheme. Leuven: Leuven University Press.

van Leeuwen, M. H. D., Maas, I., \& Miles, A. (2002). HISCO: Historical International Standard Classification of Occupations. Leuven: Leuven University Press. 
Figure 1. Life-time net migration pattern* by socioeconomic status (women aged 15-54)

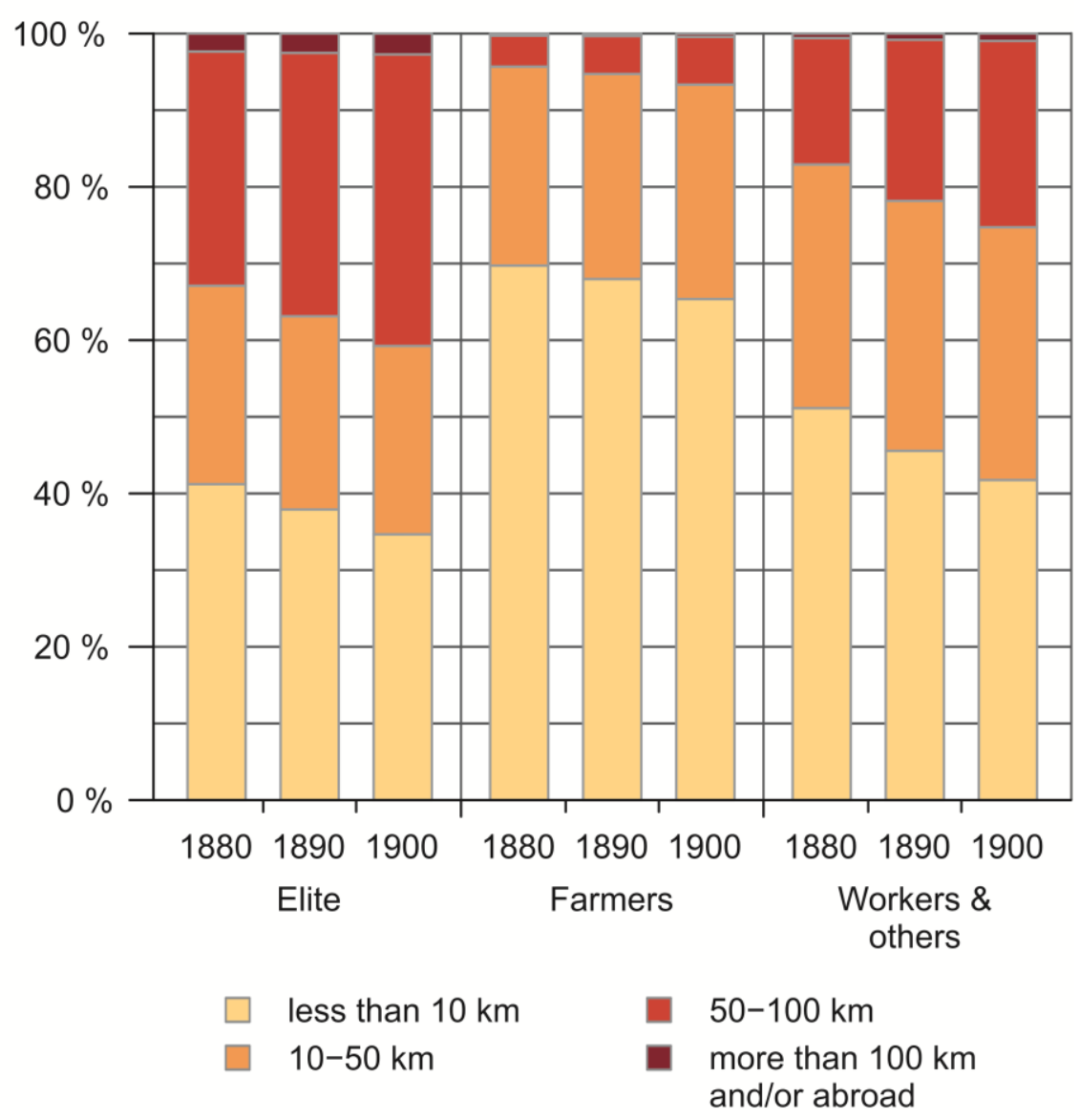

* For persons born in Sweden measured by calculating the spherical distances between the parish of birth and parish of residence.

Source: Micro-level census data, SweCens, The Swedish National Archives 
Figure 2. Change in child-woman ratio (CWR) in percent by socioeconomic status (1880-1900)

a) Total

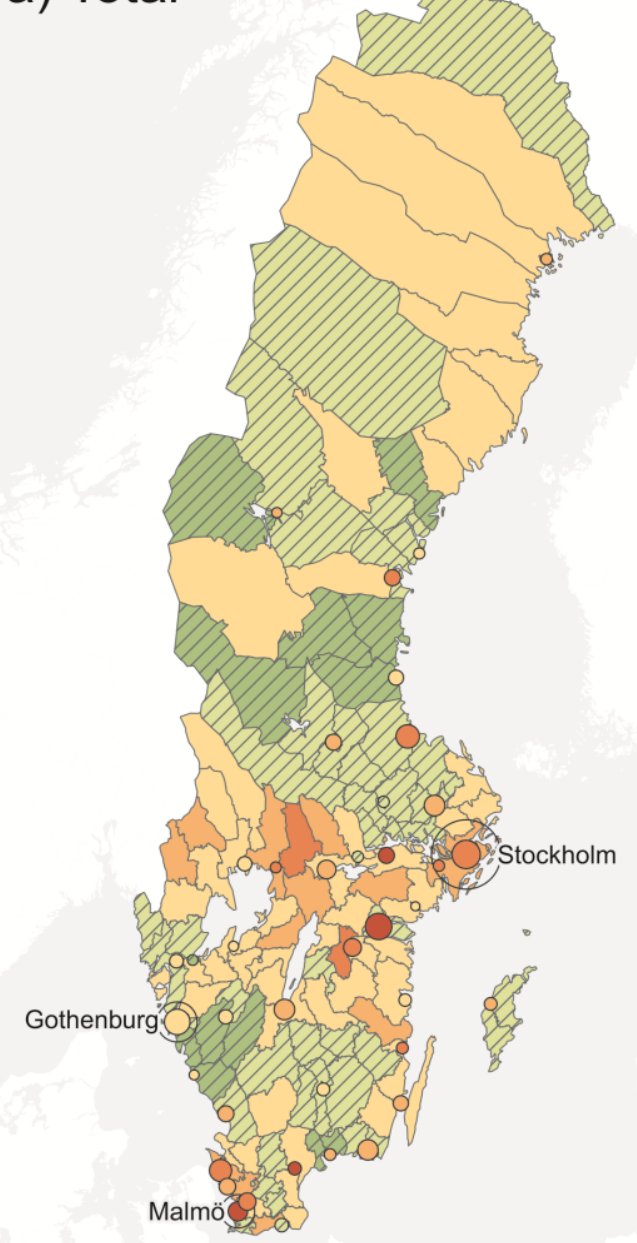

b) Elite

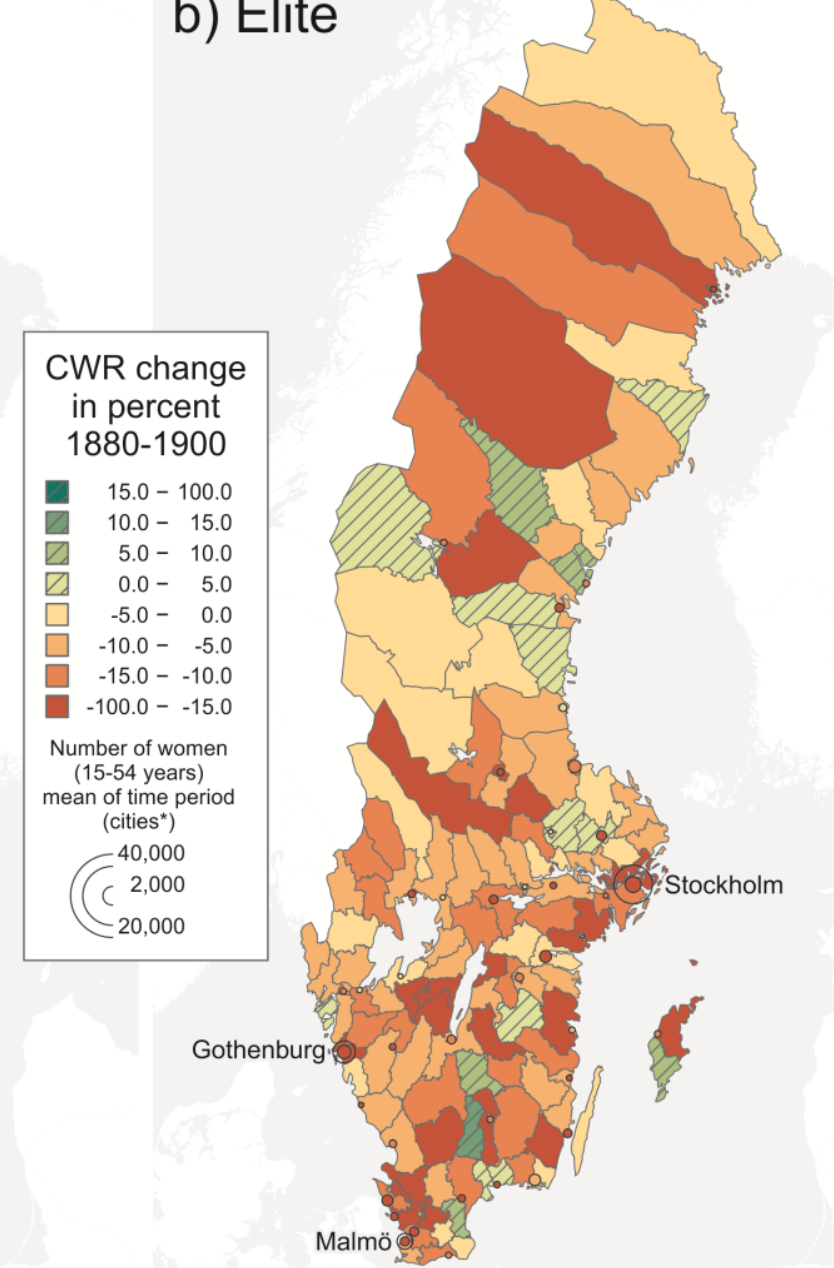



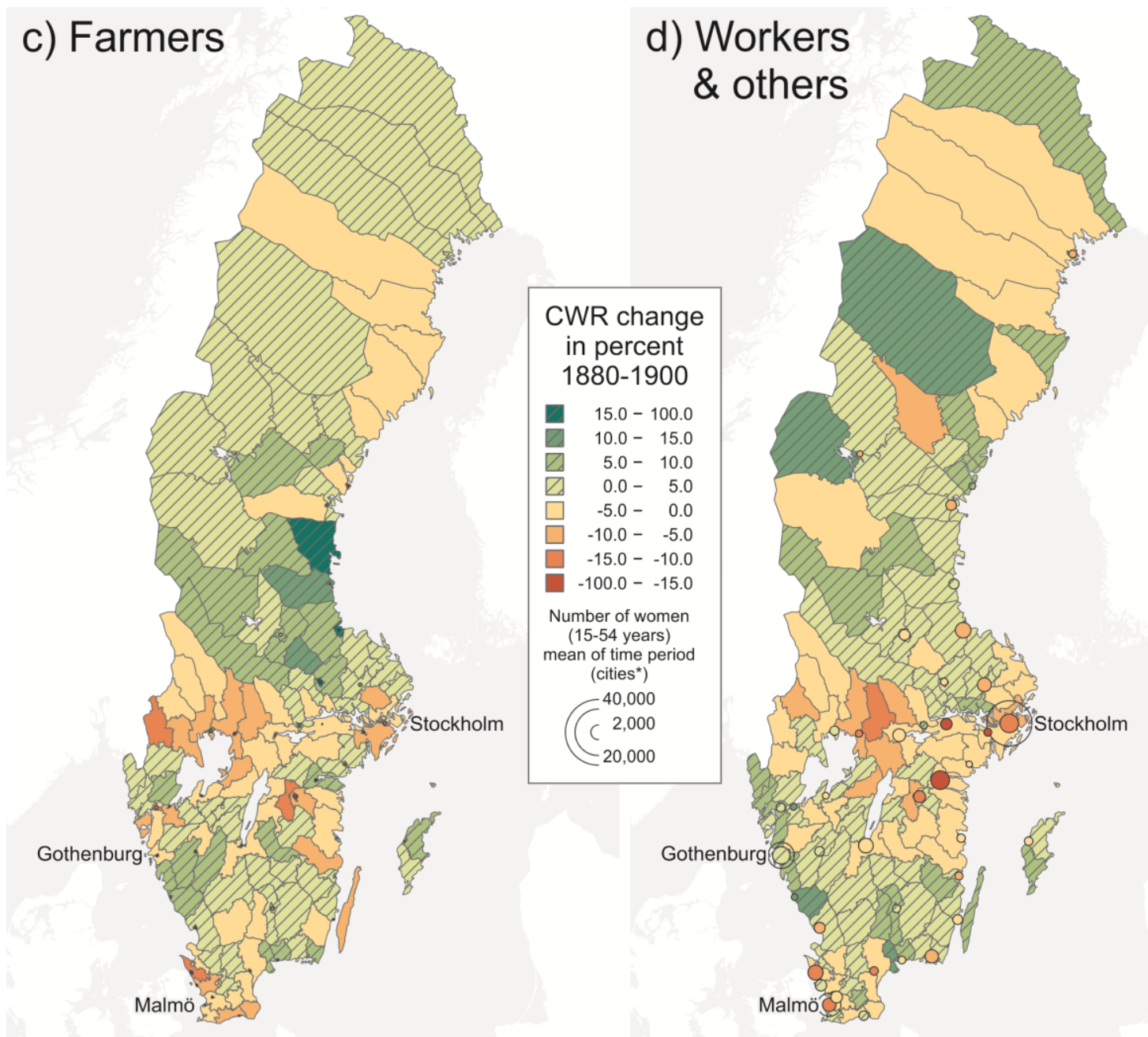

Note: The CWRs have been age-standardized using the age structure of the female population aged 15-54 in 1890 as a reference. Cities that formed their own judicial districts and had more than 5,000 inhabitants in 1900 are highlighted with circles that vary proportionally by the number of women aged 15-54. For the three biggest cities, we left the outer part of the circle transparent in order to avoid that surrounding regions are completely covered by the circle.

Source: Micro-level census data, SweCens, The Swedish National Archives Base Map: Riksarkivet (2016), MPIDR Population History GIS Collection (2014) 
Table 1. Distribution of covariates (\%)

\begin{tabular}{|c|c|c|c|}
\hline & 1880 & 1890 & 1900 \\
\hline \multicolumn{4}{|l|}{ Individual-level covariates } \\
\hline \multicolumn{4}{|l|}{ Age of woman } \\
\hline $15-19$ years & 0.4 & 0.4 & 0.4 \\
\hline $20-24$ years & 6.0 & 5.4 & 6.5 \\
\hline $25-29$ years & 13.5 & 14.1 & 13.6 \\
\hline $30-34$ years & 16.8 & 17.9 & 15.9 \\
\hline $35-39$ years & 17.8 & 17.3 & 18.2 \\
\hline $40-44$ years & 16.2 & 16.2 & 17.4 \\
\hline $45-49$ years & 15.7 & 15.4 & 15.0 \\
\hline $50-54$ years & 13.7 & 13.2 & 13.0 \\
\hline \multicolumn{4}{|l|}{ Age difference between spouses } \\
\hline Wife older & 27.9 & 26.9 & 26.0 \\
\hline Husband $0-2$ years older & 21.3 & 22.0 & 22.7 \\
\hline Husband 3-6 years older & 25.2 & 25.6 & 26.3 \\
\hline Husband $>6$ years older & 25.6 & 25.6 & 24.9 \\
\hline \multicolumn{4}{|l|}{ Children $>4$ years old in household } \\
\hline No & 30.9 & 29.9 & 29.6 \\
\hline Yes & 69.1 & 70.1 & 70.4 \\
\hline \multicolumn{4}{|l|}{ Husband household head } \\
\hline Yes & 96.0 & 96.2 & 96.9 \\
\hline No & 4.0 & 3.8 & 3.1 \\
\hline \multicolumn{4}{|l|}{ Socioeconomic status } \\
\hline Elite & 10.2 & 11.9 & 14.0 \\
\hline Farmers & 41.2 & 37.5 & 32.4 \\
\hline Skilled Workers & 9.4 & 11.2 & 13.0 \\
\hline Lower Skilled Workers & 8.2 & 10.8 & 13.7 \\
\hline Unskilled Workers & 24.2 & 23.1 & 21.7 \\
\hline Others & 6.9 & 5.5 & 5.1 \\
\hline \multicolumn{4}{|l|}{ Woman employed } \\
\hline No & 99.6 & 99.5 & 99.4 \\
\hline Yes & 0.4 & 0.5 & 0.6 \\
\hline \multicolumn{4}{|l|}{ Distance from parish of birth } \\
\hline Less than $10 \mathrm{~km}$ & 57.8 & 53.1 & 48.4 \\
\hline $10-50 \mathrm{~km}$ & 28.8 & 29.5 & 30.2 \\
\hline More than $50 \mathrm{~km}$ & 12.8 & 16.6 & 20.4 \\
\hline Born abroad & 0.6 & 0.8 & 1.0 \\
\hline \multicolumn{4}{|l|}{ Parish-level covariates } \\
\hline \multicolumn{4}{|l|}{ Female labor force rate } \\
\hline Low (1st quartile) & 25.3 & 24.1 & 22.0 \\
\hline Medium (2nd and 3rd quartiles) & 48.0 & 47.2 & 45.1 \\
\hline High (4th quartile) & 26.7 & 28.8 & 32.9 \\
\hline \multicolumn{4}{|l|}{ Education rate (teacher/child ratio) } \\
\hline Low (1st quartile) & 21.6 & 22.3 & 22.9 \\
\hline Medium (2nd and 3rd quartiles) & 59.3 & 55.4 & 58.9 \\
\hline High (4th quartile) & 19.2 & 22.3 & 18.2 \\
\hline \multicolumn{4}{|l|}{ Proportion employed in industry } \\
\hline Low (1st quartile) & 19.3 & 17.5 & 15.9 \\
\hline Medium (2nd and 3rd quartiles) & 43.9 & 40.3 & 36.6 \\
\hline High (4th quartile) & 36.8 & 42.2 & 47.5 \\
\hline
\end{tabular}


Proportion of migrants born more than

$100 \mathrm{~km}$ away and/or abroad

Low (1st quartile)

Medium (2nd and 3rd quartiles)

High (4th quartile)

17.2

47.0

14.6

44.5

41.0

13.1

35.8

76.4

9.3

7.3

7.1

71.6

8.4

9.8

10.3

3.4

2.2

5.6

7.2

9.2

2.0

2.7

7.2

1.3

4.9

6.1

1.3

11.6

4.3

30.9

580,849

2,435
5.2

2.2

5.8

7.4

8.8

2.8

2.5

6.5

1.5

4.6

6.1

1.2

12.9

4.9

27.9

586,918

2,435
40.0

46.9

67.1

8.4

12.2

12.2

5.9

2.3

5.6

7.5

9.1

3.2

2.3

6.3

1.9

4.6

5.8

1.1

12.8

5.6

25.9

\begin{tabular}{lrr} 
Number of women & 2,435 & $2,919,096$ \\
Number of parishes & 2,435 & 2,435 \\
\hline
\end{tabular}

Source: Micro-level census data, SweCens, The Swedish National Archives 
Table 2. Child-woman ratios by socioeconomic status

\begin{tabular}{lccc|ccc}
\hline & \multicolumn{3}{c|}{ Not age-standardized } & \multicolumn{3}{c}{ Age-standardized } \\
\hline & $\mathbf{1 8 8 0}$ & $\mathbf{1 8 9 0}$ & $\mathbf{1 9 0 0}$ & $\mathbf{1 8 8 0}$ & $\mathbf{1 8 9 0}$ & $\mathbf{1 9 0 0}$ \\
\hline Socioeconomic status & & & & & & \\
$\quad$ Elite & 0.87 & 0.82 & 0.73 & 0.84 & 0.80 & 0.73 \\
$\quad$ Farmers & 0.85 & 0.85 & 0.83 & 0.92 & 0.92 & 0.93 \\
$\quad$ Skilled workers & 0.93 & 0.93 & 0.87 & 0.90 & 0.89 & 0.84 \\
$\quad$ Lower skilled workers & 1.00 & 1.02 & 0.97 & 0.93 & 0.93 & 0.89 \\
$\quad$ Unskilled workers & 0.89 & 0.94 & 0.91 & 0.87 & 0.89 & 0.86 \\
Others & 0.75 & 0.73 & 0.74 & 0.80 & 0.78 & 0.77 \\
Total & & & & & & \\
\hline
\end{tabular}

Source: Micro-level census data, SweCens, The Swedish National Archives 
Table 3. Model estimates for the number of children aged 0-4 per married women aged 15-54

\begin{tabular}{|c|c|c|c|c|c|c|}
\hline & \multicolumn{2}{|c|}{1880} & \multicolumn{2}{|c|}{1890} & \multicolumn{2}{|c|}{1900} \\
\hline & coef. & p-value & coef. & p-value & coef. & p-value \\
\hline \multicolumn{7}{|l|}{ Individual-level covariates } \\
\hline \multicolumn{7}{|l|}{ Age of woman } \\
\hline $15-19$ years & -0.605 & 0.000 & -0.590 & 0.000 & -0.478 & 0.000 \\
\hline $20-24$ years & -0.214 & 0.000 & -0.151 & 0.000 & -0.102 & 0.000 \\
\hline $25-29$ years & 0.054 & 0.000 & 0.079 & 0.000 & 0.119 & 0.000 \\
\hline $30-34$ years & ref. & & ref. & & ref. & \\
\hline $35-39$ years & -0.207 & 0.000 & -0.218 & 0.000 & -0.221 & 0.000 \\
\hline $40-44$ years & -0.571 & 0.000 & -0.584 & 0.000 & -0.575 & 0.000 \\
\hline $45-49$ years & -1.116 & 0.000 & -1.130 & 0.000 & -1.100 & 0.000 \\
\hline $50-54$ years & -1.404 & 0.000 & -1.397 & 0.000 & -1.353 & 0.000 \\
\hline \multicolumn{7}{|l|}{ Age difference between spouses } \\
\hline Wife older & 0.026 & 0.000 & 0.028 & 0.000 & 0.041 & 0.000 \\
\hline Husband $0-2$ years older & ref. & & ref. & & ref. & \\
\hline Husband 3-6 years older & -0.017 & 0.000 & -0.027 & 0.000 & -0.019 & 0.000 \\
\hline Husband $>6$ years older & -0.083 & 0.000 & -0.102 & 0.000 & -0.083 & 0.000 \\
\hline \multicolumn{7}{|l|}{ Children $>4$ years old in household } \\
\hline No & ref. & & ref. & & ref. & \\
\hline Yes & 0.252 & 0.000 & 0.270 & 0.000 & 0.251 & 0.000 \\
\hline \multicolumn{7}{|l|}{ Husband household head } \\
\hline Yes & ref. & & ref. & & ref. & \\
\hline No & -0.152 & 0.000 & -0.145 & 0.000 & -0.157 & 0.000 \\
\hline \multicolumn{7}{|l|}{ Socioeconomic status } \\
\hline Elite & ref. & & ref. & & ref. & \\
\hline Farmers & 0.010 & 0.008 & 0.049 & 0.000 & 0.086 & 0.000 \\
\hline Skille & 0.050 & 0.000 & 0.086 & 0.000 & 0.096 & 0.000 \\
\hline vorkers & 0.059 & 0.000 & 0.096 & 0.000 & 0.114 & 0.000 \\
\hline Unskil & 0.005 & 0.178 & 0.060 & 0.000 & 0.090 & 0.000 \\
\hline Others & -0.022 & 0.000 & -0.001 & 0.858 & 0.035 & 0.000 \\
\hline \multicolumn{7}{|l|}{ Woman employed } \\
\hline No & ref. & & ref. & & ref. & \\
\hline Yes & -0.187 & 0.000 & -0.181 & 0.000 & -0.153 & 0.000 \\
\hline \multicolumn{7}{|l|}{ Distance from parish of birth } \\
\hline Less than $10 \mathrm{~km}$ & ref. & & ref. & & ref. & \\
\hline $10-50 \mathrm{~km}$ & 0.024 & 0.000 & 0.028 & 0.000 & 0.029 & 0.000 \\
\hline More than $50 \mathrm{~km}$ & 0.048 & 0.000 & 0.035 & 0.000 & 0.015 & 0.000 \\
\hline Born abroad & 0.014 & 0.256 & -0.017 & 0.140 & -0.029 & 0.004 \\
\hline \multicolumn{7}{|l|}{ Parish-level covariates } \\
\hline \multicolumn{7}{|l|}{ Female labor force rate } \\
\hline Low (1st quartile) & -0.006 & 0.180 & -0.004 & 0.324 & 0.010 & 0.017 \\
\hline Medium (2nd and 3rd quartiles & ref. & & ref. & & ref. & \\
\hline High (4th quartile) & -0.006 & 0.174 & -0.009 & 0.064 & -0.014 & 0.002 \\
\hline \multicolumn{7}{|l|}{ Education rate (teacher/child ratio) } \\
\hline Low (1st quartile) & -0.011 & 0.009 & 0.008 & 0.056 & 0.005 & 0.211 \\
\hline Medium (2nd and 3rd quartiles) & ref. & & ref. & & ref. & \\
\hline High (4th quartile) & -0.011 & 0.012 & -0.011 & 0.015 & -0.027 & 0.000 \\
\hline
\end{tabular}




\begin{tabular}{|c|c|c|c|c|c|c|}
\hline \multicolumn{7}{|l|}{ Proportion employed in industry } \\
\hline Low (1st quartile) & 0.021 & 0.000 & 0.017 & 0.000 & 0.016 & 0.001 \\
\hline Medium (2nd and 3rd quartiles) & ref. & & ref. & & ref. & \\
\hline High (4th quartile) & 0.001 & 0.789 & -0.009 & 0.042 & -0.005 & 0.224 \\
\hline \multirow{2}{*}{\multicolumn{7}{|c|}{$\begin{array}{l}\text { Proportion of migrants born more } \\
\text { than } 100 \mathrm{~km} \text { away and/or abroad }\end{array}$}} \\
\hline & & & & & & \\
\hline Low (1st quartile) & 0.001 & 0.802 & 0.001 & 0.878 & -0.003 & 0.498 \\
\hline Medium (2nd and 3rd quartiles) & ref. & & ref. & & ref. & \\
\hline High (4th quartile) & -0.004 & 0.458 & -0.001 & 0.887 & -0.009 & 0.044 \\
\hline \multicolumn{7}{|l|}{ Population density per $\mathbf{k m}^{2}$} \\
\hline Less than 50 & ref. & & ref. & & ref. & \\
\hline $50-100$ & -0.027 & 0.000 & -0.021 & 0.002 & -0.035 & 0.000 \\
\hline $100-1000$ & -0.057 & 0.000 & -0.049 & 0.000 & -0.057 & 0.000 \\
\hline More than 1000 & -0.066 & 0.002 & -0.081 & 0.000 & -0.104 & 0.000 \\
\hline \multicolumn{7}{|l|}{ Regional dummies } \\
\hline Less than $10 \mathrm{~km}$ from Stockholm & ref. & & ref. & & ref. & \\
\hline 10-50 km from Stockholm & 0.033 & 0.377 & 0.023 & 0.520 & 0.071 & 0.035 \\
\hline $50-100 \mathrm{~km}$ from Stockholm & -0.004 & 0.909 & -0.027 & 0.437 & 0.053 & 0.108 \\
\hline $100-150 \mathrm{~km}$ from Stockholm & 0.013 & 0.723 & -0.003 & 0.930 & 0.070 & 0.034 \\
\hline $150-200 \mathrm{~km}$ from Stockholm & 0.082 & 0.025 & 0.053 & 0.127 & 0.111 & 0.001 \\
\hline \multicolumn{7}{|l|}{ Less than $10 \mathrm{~km}$ from } \\
\hline Gothenburg & 0.161 & 0.000 & 0.169 & 0.000 & 0.254 & 0.000 \\
\hline $10-50 \mathrm{~km}$ from Gothenburg & 0.164 & 0.000 & 0.176 & 0.000 & 0.246 & 0.000 \\
\hline $50-100 \mathrm{~km}$ from Gothenburg & 0.164 & 0.000 & 0.153 & 0.000 & 0.248 & 0.000 \\
\hline Less than $10 \mathrm{~km}$ from Malmö & 0.154 & 0.000 & 0.076 & 0.054 & 0.195 & 0.000 \\
\hline $10-50 \mathrm{~km}$ from Malmö & 0.111 & 0.002 & 0.045 & 0.191 & 0.157 & 0.000 \\
\hline 50-100 km from Malmö & 0.135 & 0.000 & 0.094 & 0.007 & 0.171 & 0.000 \\
\hline Gotland & -0.115 & 0.002 & -0.130 & 0.000 & -0.016 & 0.651 \\
\hline \multicolumn{7}{|l|}{ Southern Norrland \& } \\
\hline Kopparberg county & 0.094 & 0.010 & 0.081 & 0.018 & 0.167 & 0.000 \\
\hline Northern Norrland & 0.258 & 0.000 & 0.219 & 0.000 & 0.298 & 0.000 \\
\hline $\begin{array}{l}\text { Other areas } \\
\text { (central \& southern Sweden) }\end{array}$ & 0.164 & 0.000 & 0.132 & 0.000 & 0.217 & 0.000 \\
\hline Constant & 1.103 & 0.000 & 1.087 & 0.000 & 0.954 & 0.000 \\
\hline Number w & 580,849 & & 586,198 & & 619,096 & \\
\hline Number of parishes & 2,435 & & 2,435 & & 2,435 & \\
\hline
\end{tabular}

\begin{tabular}{lllllll}
\hline $\begin{array}{l}\text { Spatial autocorrelation } \\
\text { diagnostics }\end{array}$ & & & & & & \\
Moran's I dependent variable* & 0.465 & 0.000 & 0.471 & 0.000 & 0.414 & 0.000 \\
Moran's I residuals* & 0.194 & 0.000 & 0.162 & 0.000 & 0.142 & 0.000 \\
\hline
\end{tabular}

* Measured at parish level, neighborhood is defined as five nearest neighbors.

Source: Micro-level census data, SweCens, The Swedish National Archives 
Table 4. Models by socioeconomic status: estimates for the number of children aged 0-4 per married women aged 15-54

\begin{tabular}{|c|c|c|c|c|c|c|c|c|c|c|c|c|c|c|c|c|c|c|}
\hline & \multirow{2}{*}{\multicolumn{4}{|c|}{$\begin{array}{l}\text { Elite } \\
1890\end{array}$}} & \multirow{2}{*}{\multicolumn{2}{|c|}{1900}} & \multirow{2}{*}{\multicolumn{4}{|c|}{$\begin{array}{c}\text { Farmers } \\
1890\end{array}$}} & \multirow{2}{*}{\multicolumn{2}{|c|}{1900}} & \multicolumn{6}{|c|}{ Workers and others } \\
\hline & & & & & & & & & & & & & \multicolumn{2}{|c|}{1880} & \multicolumn{2}{|c|}{1890} & \multicolumn{2}{|c|}{1900} \\
\hline & \multicolumn{2}{|c|}{ coef. p-value } & coef. & p-value & coef. & p-value & coef. & p-value & coef. & p-value & coef. & p-value & coef. & p-value & coef. & p-value & coef. & p-value \\
\hline \multirow{2}{*}{\multicolumn{19}{|c|}{$\begin{array}{l}\text { Individual-level covariates } \\
\text { Age of woman }\end{array}$}} \\
\hline & & & & & & & & & & & & & & & & & & \\
\hline $15-19$ years & -0.619 & 0.000 & -0.676 & 0.000 & -0.394 & 0.000 & -0.740 & 0.000 & -0.713 & 0.000 & -0.645 & 0.000 & -0.541 & 0.000 & -0.542 & 0.000 & -0.445 & 0.000 \\
\hline $20-24$ years & -0.235 & 0.000 & -0.138 & 0.000 & -0.127 & 0.000 & -0.216 & 0.000 & -0.163 & 0.000 & -0.142 & 0.000 & -0.205 & 0.000 & -0.144 & 0.000 & -0.076 & 0.000 \\
\hline 25-29 years & 0.075 & 0.000 & 0.100 & 0.000 & 0.122 & 0.000 & 0.071 & 0.000 & 0.093 & 0.000 & 0.122 & 0.000 & 0.043 & 0.000 & 0.071 & 0.000 & 0.125 & 0.000 \\
\hline $30-34$ years & ref. & & ref. & & ref. & & ref. & & ref. & & ref. & & ref. & & ref. & & ref. & \\
\hline $35-39$ years & -0.250 & 0.000 & -0.262 & 0.000 & -0.239 & 0.000 & -0.217 & 0.000 & -0.223 & 0.000 & -0.226 & 0.000 & -0.191 & 0.000 & -0.207 & 0.000 & -0.217 & 0.000 \\
\hline $40-44$ years & -0.651 & 0.000 & -0.640 & 0.000 & -0.607 & 0.000 & -0.578 & 0.000 & -0.598 & 0.000 & -0.602 & 0.000 & -0.552 & 0.000 & -0.564 & 0.000 & -0.555 & 0.000 \\
\hline $45-49$ years & -1.159 & 0.000 & -1.119 & 0.000 & -1.032 & 0.000 & -1.137 & 0.000 & -1.154 & 0.000 & -1.165 & 0.000 & -1.095 & 0.000 & -1.121 & 0.000 & -1.079 & 0.000 \\
\hline $50-54$ years & -1.402 & 0.000 & -1.343 & 0.000 & -1.231 & 0.000 & -1.439 & 0.000 & -1.438 & 0.000 & -1.442 & 0.000 & -1.379 & 0.000 & -1.383 & 0.000 & -1.327 & 0.000 \\
\hline \multicolumn{19}{|l|}{ Age difference between spouses } \\
\hline Wife older & 0.036 & 0.001 & 0.055 & 0.000 & 0.052 & 0.000 & 0.032 & 0.000 & 0.040 & 0.000 & 0.042 & 0.000 & 0.021 & 0.000 & 0.016 & 0.000 & 0.038 & 0.000 \\
\hline Husband $0-2$ years older & ref. & & ref. & & ref. & & ref. & & ref. & & ref. & & ref. & & ref. & & ref. & \\
\hline Husband 3-6 years older & -0.036 & 0.000 & -0.030 & 0.001 & -0.031 & 0.000 & -0.023 & 0.000 & -0.036 & 0.000 & -0.033 & 0.000 & -0.010 & 0.014 & -0.022 & 0.000 & -0.008 & 0.033 \\
\hline Husband $>6$ years older & -0.100 & 0.000 & -0.136 & 0.000 & -0.109 & 0.000 & -0.092 & 0.000 & -0.104 & 0.000 & -0.099 & 0.000 & -0.078 & 0.000 & -0.096 & 0.000 & -0.066 & 0.000 \\
\hline \multicolumn{19}{|l|}{ Children $>4$ years old in household } \\
\hline No & ref. & & ref. & & ref. & & ref. & & ref. & & ref. & & ref. & & ref. & & ref. & \\
\hline Yes & 0.266 & 0.000 & 0.278 & 0.000 & 0.220 & 0.000 & 0.252 & 0.000 & 0.262 & 0.000 & 0.249 & 0.000 & 0.250 & 0.000 & 0.273 & 0.000 & 0.261 & 0.000 \\
\hline \multicolumn{19}{|l|}{ Hus band hous ehold head } \\
\hline Yes & ref. & & ref. & & ref. & & ref. & & ref. & & ref. & & ref. & & ref. & & ref. & \\
\hline No & -0.220 & 0.000 & -0.122 & 0.000 & -0.144 & 0.000 & -0.076 & 0.000 & -0.085 & 0.000 & -0.092 & 0.000 & -0.185 & 0.000 & -0.196 & 0.000 & -0.201 & 0.000 \\
\hline Woman employed & & & & & & & & & & & & & & & & & & \\
\hline No & ref. & & ref. & & ref. & & ref. & & ref. & & ref. & & ref. & & ref. & & ref. & \\
\hline Yes & -0.165 & 0.000 & -0.168 & 0.000 & -0.147 & 0.000 & -0.135 & 0.004 & -0.162 & 0.000 & -0.140 & 0.000 & -0.201 & 0.000 & -0.192 & 0.000 & -0.162 & 0.000 \\
\hline Distanc & & & & & & & & & & & & & & & & & & \\
\hline Less than $10 \mathrm{~km}$ & ref. & & ref. & & ref. & & ref. & & ref. & & ref. & & ref. & & ref. & & ref. & \\
\hline $10-50 \mathrm{~km}$ & 0.028 & 0.001 & 0.012 & 0.129 & 0.030 & 0.000 & 0.028 & 0.000 & 0.031 & 0.000 & 0.034 & 0.000 & 0.019 & 0.000 & 0.024 & 0.000 & 0.022 & 0.000 \\
\hline More than $50 \mathrm{~km}$ & 0.036 & 0.000 & -0.012 & 0.123 & -0.017 & 0.010 & 0.069 & 0.000 & 0.056 & 0.000 & 0.034 & 0.000 & 0.047 & 0.000 & 0.040 & 0.000 & 0.022 & 0.000 \\
\hline Born abroad & -0.009 & 0.698 & -0.080 & 0.000 & -0.045 & 0.008 & 0.112 & 0.000 & 0.065 & 0.020 & 0.004 & 0.897 & -0.005 & 0.802 & 0.010 & 0.541 & -0.018 & 0.202 \\
\hline Parish-level cov: & & & & & & & & & & & & & & & & & & \\
\hline Female labor force rate & & & & & & & & & & & & & & & & & & \\
\hline Low (1st quartile) & 0.008 & 0.491 & 0.020 & 0.055 & 0.051 & 0.000 & -0.008 & 0.144 & -0.004 & 0.521 & 0.005 & 0.331 & -0.006 & 0.244 & -0.008 & 0.152 & 0.013 & 0.011 \\
\hline Med & ref. & & ref. & & & & & & & & & & & & & & ref. & \\
\hline High (4th quartile) & -0.017 & 0.074 & -0.016 & 0.106 & -0.015 & 0.177 & -0.005 & 0.444 & -0.009 & 0.186 & -0.014 & 0.040 & -0.005 & 0.326 & -0.005 & 0.409 & -0.010 & 0.040 \\
\hline Educatio & & & & & & & & & & & & & & & & & & \\
\hline Low (1st quartile) & -0.009 & 0.367 & 0.005 & 0.613 & 0.011 & 0.292 & -0.009 & 0.106 & 0.008 & 0.194 & 0.000 & 0.937 & -0.012 & 0.010 & 0.006 & 0.233 & 0.010 & 0.040 \\
\hline Medium (2nd and 3rd quartiles) & ref. & & ref. & & & & ref. & & & & ref. & & & & ref. & & ref. & \\
\hline High (4th quartile) & 0.003 & 0.793 & -0.004 & 0.674 & -0.014 & 0.224 & -0.013 & 0.028 & -0.014 & 0.029 & -0.033 & 0.000 & -0.008 & 0.121 & -0.006 & 0.268 & -0.021 & 0.000 \\
\hline
\end{tabular}


Proportion employed in industry Low (1st quartile)

Medium (2nd and 3rd quartiles) High (4th quartile)

Proportion of migrants born more than

$100 \mathrm{~km}$ away and/or abroad

Low (1st quartile)

Medium(2nd and 3rd quartiles)

High (4th quartile)

Population density per $\mathbf{k m}^{2}$

Less than 50

$50-100$

$100-1000$

More than 1000

Regional dummies

Less than $10 \mathrm{~km}$ from Stockholm

$10-50 \mathrm{~km}$ from Stockholm

$50-100 \mathrm{~km}$ from Stockholm

$100-150 \mathrm{~km}$ from Stockholm

150-200 km from Stockholn

Less than $10 \mathrm{~km}$ from Göteborg

$10-50 \mathrm{~km}$ from Göteborg

$50-100 \mathrm{~km}$ from Göteborg

Less than $10 \mathrm{~km}$ from Malmö

$10-50 \mathrm{~km}$ from Malmö

$50-100 \mathrm{~km}$ from Malmö

Gotland

Southern Norrland \& Kopparberg county

Northern Nor

Other areas (central \& southern Sweden)

Constant

Spatial autocorrelation diagnostics

Moran's I dependent variable*

Moran's I residuals*

* Measured at parish level, neighborhood is defined as five nearest neighbors. Parishes with no observations are excluded from the calculation of the Mo-

ran's I prior to constructing the spatial weight matrices in which information on the five nearest neighboring regions is stored. As a result, each region has

five nearest neighbors with at least one women each.

Source: Micro-level census data, SweCens, The Swedish National Archives

\begin{tabular}{|c|c|c|c|c|c|c|c|c|c|c|c|c|c|c|c|c|c|}
\hline $\begin{array}{r}0.022 \\
\text { ref. }\end{array}$ & 0.088 & $\begin{array}{r}0.034 \\
\text { ref. }\end{array}$ & 0.008 & $\begin{array}{r}-0.002 \\
\text { ref. }\end{array}$ & 0.853 & $\begin{array}{r}0.024 \\
\text { ref. }\end{array}$ & 0.000 & $\begin{array}{r}0.004 \\
\text { ref. }\end{array}$ & 0.506 & $\begin{array}{r}0.018 \\
\text { ref. }\end{array}$ & 0.002 & $\begin{array}{r}0.016 \\
\text { ref. }\end{array}$ & 0.007 & $\begin{array}{r}0.023 \\
\text { ref. }\end{array}$ & 0.000 & $\begin{array}{r}0.009 \\
\text { ref. }\end{array}$ & 0.122 \\
\hline 0.002 & 0.823 & -0.015 & 0.117 & -0.022 & 0.046 & 0.006 & 0.322 & -0.010 & 0.136 & 0.002 & 0.700 & 0.001 & 0.797 & -0.005 & 0.349 & -0.005 & 0.326 \\
\hline $\begin{array}{r}0.035 \\
\text { ref. }\end{array}$ & 0.008 & $\begin{array}{r}0.022 \\
\text { ref. }\end{array}$ & 091 & $\begin{array}{r}0.015 \\
\text { ref. }\end{array}$ & 0.268 & $\begin{array}{r}0.001 \\
\text { ref. }\end{array}$ & 869 & $\begin{array}{r}0.002 \\
\text { ref. }\end{array}$ & .736 & $\begin{array}{r}-0.013 \\
\text { ref. }\end{array}$ & 0.034 & $\begin{array}{r}-0.006 \\
\text { ref. }\end{array}$ & 0.305 & $\begin{array}{r}-0.007 \\
\text { ref. }\end{array}$ & .270 & $\begin{array}{r}0.005 \\
\text { ref. }\end{array}$ & 469 \\
\hline-0.033 & 0.002 & -0.017 & 0.102 & -0.017 & 0.146 & -0.001 & 0.834 & 0.006 & 0.422 & 0.001 & 0.844 & -0.003 & 0.557 & -0.006 & 0.257 & -0.020 & 0.000 \\
\hline ref. & & ref. & & ref. & & ref. & & ref. & & ref. & & ref. & & IE⿺辶. & & & \\
\hline-0.036 & 0.007 & 0.001 & 0.943 & -0.015 & .351 & -0.016 & 0.086 & -0.036 & 0.001 & -0.051 & 0.000 & -0.029 & 0.000 & -0.004 & 0.604 & -0.024 & 0.001 \\
\hline-0.051 & 0.000 & -0.042 & 002 & -0.045 & .010 & -0.017 & 383 & -0.037 & 0.045 & -0.049 & 0.004 & -0.054 & 000 & -0.045 & .000 & -0.055 & .000 \\
\hline-0.047 & 0.020 & -0.100 & 0.000 & -0.107 & .001 & -0.088 & 0.125 & -0.097 & 0.117 & -0.015 & 0.778 & -0.063 & 0.001 & -0.068 & 0.000 & -0.100 & 0.000 \\
\hline ref. & & re & & ref. & & re & & re & & re & & Fet. & & & & & \\
\hline 0.082 & 0.004 & 0.050 & 254 & 0.072 & 285 & 0.031 & 0.689 & 0.022 & 0.790 & 0.195 & 0.017 & 0.039 & 0.251 & 0.033 & 0.342 & 0.063 & 0.023 \\
\hline 0.045 & 0.042 & 0009 & 220 & 0.078 & 233 & 0.025 & 747 & -0.013 & 08 & 0.190 & 0.018 & 0.000 & .998 & -0.016 & 23 & 0.041 & 123 \\
\hline 0.090 & 0.000 & 026 & 52: & 0.083 & 201 & 0.027 & & 0.019 & & & 0.011 & 0.021 & 0 & 0.009 & 95 & 0.067 & 011 \\
\hline 0.123 & 0.000 & 0.072 & 076 & 0.103 & 115 & 0.113 & 39 & 0.084 & 0.304 & & 0.001 & 0.084 & 1 & 0.060 & 0.072 & 0.103 & .000 \\
\hline 0.179 & 0.000 & 2 & 0.00 & 0.224 & 004 & 0.190 & 7 & 0.258 & 0. & 0. & 0.000 & 0. & & 0. & 0 & 88 & 000 \\
\hline 0.201 & 0.000 & 137 & 002 & 0.238 & 000 & 0.216 & 5 & 0.236 & 0.004 & 435 & 0.000 & 0.138 & 0 & 0.159 & .000 & 0.201 & .000 \\
\hline 0.180 & 0.000 & 0.139 & 001 & 0.194 & 003 & 0.209 & 0.006 & 0.200 & 0.015 & 0.425 & 0.000 & 0.155 & .000 & 0.152 & .000 & 0.231 & 0.000 \\
\hline 0.158 & 0000 & 0.146 & 0 & & 027 & 0.139 & 00 & 0.003 & 00 & 0.295 & 0.001 & 3 & & 0.098 & 2 & 96 & .000 \\
\hline 0.174 & 0.000 & 043 & 0 & & 075 & 0.126 & & 0.072 & 0.3 & 0.281 & 0.000 & 0.124 & 0.0 & 0.057 & .089 & 0.168 & .000 \\
\hline 0.136 & 0.000 & 0.076 & 770 & 0. & 056 & 0.165 & 031 & 0.132 & 0.108 & 0.329 & 0.000 & 0.147 & .000 & 0.098 & .004 & 0.162 & 0.000 \\
\hline 0.032 & 0.383 & 0012 & 0 & & 500 & -0.138 & , & -0.151 & & 0.094 & 0.247 & -0.083 & م0 & -0.077 & 34 & 0.018 & 0.548 \\
\hline 0.130 & 0.000 & 0.093 & 22 & & 021 & 0.125 & 1 & 0.111 & 0.174 & 0.321 & 0.000 & 0.096 & 0.004 & 0.094 & 0.005 & 0.158 & 0.000 \\
\hline 0.233 & 0.000 & 0.150 & 0.001 & & 0.000 & 0.365 & 0.000 & 0.325 & 0.000 & 0.526 & 0.000 & 0.176 & 0.000 & 0.140 & 0.000 & 0.214 & 0.000 \\
\hline 0.187 & 0.000 & 0.124 & 0.002 & 0.182 & 0.005 & 0.207 & 0.007 & 0.174 & 0.033 & 0.384 & 0.000 & 0.158 & 0.000 & 0.132 & 0.000 & 0.206 & 0.000 \\
\hline 1.105 & 0.000 & 1.123 & 0.000 & 1.007 & 0.000 & 1.084 & 0.000 & 1.114 & 0.000 & 0.920 & 0.000 & 1.120 & 0.000 & 1.140 & 0.000 & 1.034 & 0.000 \\
\hline 59,047 & & 69,971 & & 86,593 & & 239,268 & & 220,105 & & 200,589 & & 282,534 & & 296,842 & & 331,914 & \\
\hline 2,408 & & 2,409 & & 2,416 & & 2,422 & & 2,426 & & 2,428 & & 2,435 & & 2,435 & & 2,435 & \\
\hline 0.059 & & & & & 00 & & & U.J5נ & & 81 & 0.000 & 0.276 & & 0.223 & & 0.210 & 0.000 \\
\hline-0.007 & 0.567 & 0.013 & 0.323 & -0.020 & 100 & 0.109 & 0.000 & 0.039 & 0.001 & 0.067 & 0.000 & 0.069 & 0.000 & 0.061 & 0.000 & 0.064 & 0.000 \\
\hline
\end{tabular}

